\title{
Shallow groundwater thermal sensitivity to climate change and land cover disturbances: derivation of analytical expressions and implications for stream temperature modeling
}

\author{
B. L. Kurylyk ${ }^{1, *}$, K. T. B. MacQuarrie ${ }^{1}$, D. Caissie ${ }^{2}$, and J. M. McKenzie ${ }^{3}$ \\ ${ }^{1}$ University of New Brunswick, Department of Civil Engineering and Canadian Rivers Institute, \\ Fredericton, New Brunswick, Canada \\ ${ }^{2}$ Fisheries and Oceans Canada, Gulf Fisheries Centre, Moncton, New Brunswick, Canada \\ ${ }^{3}$ McGill University, Department of Earth and Planetary Sciences, McGill University, Montreal, Quebec, Canada \\ * now at: University of Calgary, Department of Geoscience, Calgary, Alberta, Canada
}

Correspondence to: B. L. Kurylyk (barret.kurylyk@unb.ca)

Received: 28 September 2014 - Published in Hydrol. Earth Syst. Sci. Discuss.: 12 November 2014

Revised: 29 April 2015 - Accepted: 30 April 2015 - Published: 26 May 2015

\begin{abstract}
Climate change is expected to increase stream temperatures and the projected warming may alter the spatial extent of habitat for cold-water fish and other aquatic taxa. Recent studies have proposed that stream thermal sensitivities, derived from short-term air temperature variations, can be employed to infer future stream warming due to longterm climate change. However, this approach does not consider the potential for streambed heat fluxes to increase due to gradual warming of the shallow subsurface. The temperature of shallow groundwater is particularly important for the thermal regimes of groundwater-dominated streams and rivers. Also, recent studies have investigated how land surface perturbations, such as wildfires or timber harvesting, can influence stream temperatures by changing stream surface heat fluxes, but these studies have typically not considered how these surface disturbances can also alter shallow groundwater temperatures and streambed heat fluxes.

In this study, several analytical solutions to the onedimensional unsteady advection-diffusion equation for subsurface heat transport are employed to estimate the timing and magnitude of groundwater temperature changes due to seasonal and long-term variability in land surface temperatures. Groundwater thermal sensitivity formulae are proposed that accommodate different surface warming scenarios. The thermal sensitivity formulae suggest that shallow groundwater will warm in response to climate change and other surface perturbations, but the timing and magnitude
\end{abstract}

of the subsurface warming depends on the rate of surface warming, subsurface thermal properties, bulk aquifer depth, and groundwater velocity. The results also emphasize the difference between the thermal sensitivity of shallow groundwater to short-term (e.g., seasonal) and longterm (e.g., multi-decadal) land surface-temperature variability, and thus demonstrate the limitations of using short-term air and water temperature records to project future stream warming. Suggestions are provided for implementing these formulae in stream temperature models to accommodate groundwater warming.

\section{Introduction}

The water temperature of streams and rivers is an important determinant of aquatic ecosystem health due to its influence on physicochemical conditions and because many freshwater fish species can only tolerate a certain temperature range (Caissie, 2006; Elliott and Elliott, 2010; Hannah and Garner, 2015; Webb et al., 2008). Also, river thermal diversity enhances ecosystem complexity by providing thermally suitable habitat in reaches that would otherwise be uninhabitable for certain species (Cunjak et al., 2013; Ebersole et al., 2003; Kurylyk et al., 2015; Sutton et al., 2007). The thermal regimes of streams and rivers are controlled by energy fluxes across the water surface and the streambed (Fig. 1) as 


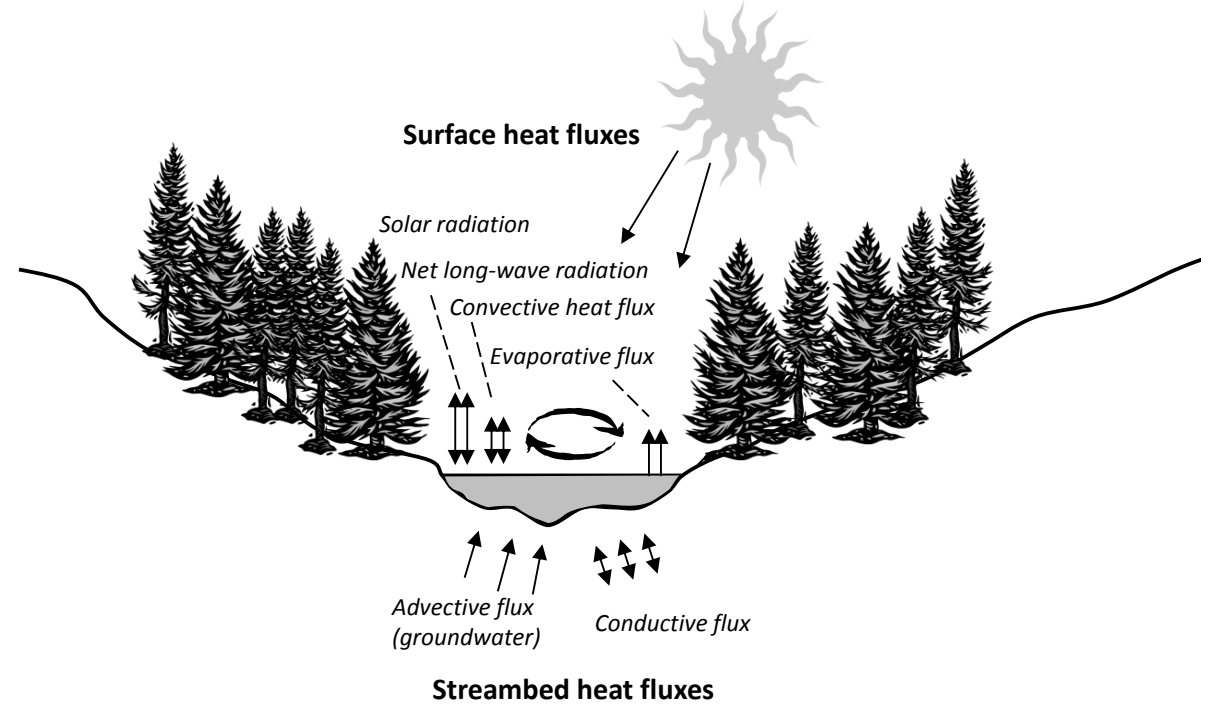

Figure 1. Heat fluxes at the water surface and streambed for the cross section of a gaining stream or river (modified from Caissie, 2006).

well as the internal structure of the stream or river network (Guenther et al., 2015; Hannah et al., 2004; Herbert et al., 2011; Leach and Moore, 2011; Poole and Berman, 2001). The total streambed heat flux is composed of conductive and advective heat fluxes, which both depend on subsurface temperatures (Caissie et al., 2014; Moore et al., 2005; St-Hilaire et al., 2000).

Large rivers tend to be dominated by surface heat fluxes, but streambed advective heat fluxes induced by groundwater-surface water interactions can influence the thermal regimes of certain headwater streams or smaller rivers (Caissie, 2006). The significance of streambed advective heat fluxes generally varies spatially and temporally within a channel and depends on, among other things, the groundwater discharge rate and the degree of shading (e.g., Brown and Hannah, 2008; Leach and Moore, 2011; Story et al., 2003). Due to the thermal inertia of the subsurface soil-water matrix, groundwater-dominated streams and rivers typically exhibit attenuated thermal responses to diel and seasonal variations in air temperature compared to surface runoff-dominated streams and rivers (Caissie et al., 2014; Constantz, 1998; Garner et al., 2014; O'Driscoll and DeWalle, 2006; Tague et al., 2007). Kelleher et al. (2012) defined the thermal sensitivity of a stream as the slope of the linear regression between air and water temperatures. These regressions are typically performed on temperature data collected for a period of at least 1 year and averaged on a daily, weekly, or monthly basis. The stream thermal sensitivity is thus a measure of the short-term (e.g., seasonal) change in water temperature in response to a short-term change in air temperature (Kelleher et al., 2012; Mayer, 2012).

Many studies have addressed the response of river and stream thermal regimes to climate change (e.g., Isaak et al., 2012; Luce et al., 2014; MacDonald et al., 2014; van Vliet et al., 2011), deforestation for land development and/or timber harvesting (e.g., Janisch et al., 2012; Moore et al., 2005; Studinski et al., 2012), and wildfires (e.g., Hitt, 2003; Isaak et al., 2010; Wagner et al., 2014). Several very recent studies have proposed that the empirical relationship (e.g., linear regression) between seasonal records of air and stream temperatures can be applied to estimate long-term stream warming due to future climate change (e.g., Caldwell et al., 2015; Gu et al., 2015; Hilderbrand et al., 2014; Trumbo et al., 2014).

Because groundwater temperature exhibits less seasonal variability than surface water temperature, it is not surprising that extrapolated stream thermal sensitivities obtained from short-term temperature data will typically indicate that the temperature of groundwater-dominated streams will be relatively insensitive to climate change. As noted by Johnson (2003), care should be taken when using air temperature correlations to explain stream temperature dynamics, as air temperature is not the dominant controlling factor in stream temperature dynamics. Rather, the high correlation between stream and air temperature arises because both variables are influenced by incoming solar radiation, the primary driver of stream temperatures (Allan and Castillo, 2007). The approach of using short-term stream thermal sensitivities to estimate multi-decadal stream warming essentially employs future air temperature as a surrogate for future stream surface heat fluxes ( $\mathrm{Gu}$ et al., 2015; Johnson et al., 2014; Mohseni and Stefan, 1999), but it ignores changes to streambed heat fluxes due to groundwater warming. Thus, the short-term relationship between air and water temperatures is not necessarily representative of the concomitant warming of the lower atmosphere and surface water bodies on inter-annual or multi-decadal timescales (Arismendi et al., 2014; Bal et al., 2014; Luce et al., 2014). 
Furthermore, many studies have investigated the response of stream thermal regimes to land surface perturbations, such as wildfires and deforestation, for the first few years following the disturbance. However, very few studies have considered how these perturbations could increase the temperature of groundwater discharge to these streams and thereby produce enhanced or sustained stream warming. In general, the common approach of ignoring future increases in groundwater temperature, and streambed heat fluxes in stream temperature models may underestimate future stream warming and associated environmental impacts (e.g., habitat loss for coldwater fish; Snyder et al., 2015).

There is increasing evidence that the thermal regimes of shallow aquifers are sensitive to climate change, permanent deforestation, and wildfires. Observed shallow groundwater temperature warming has already been related to recent trends in air temperature (an indicator of climate change) in Taiwan (Chen et al., 2011), Switzerland (Figura et al., 2011, 2014), and Germany (Menberg et al., 2014). Empirical and process-based models of energy transport in shallow aquifers have been used to suggest that future climate change will continue to warm shallow groundwater bodies (e.g., Gunawardhana and Kazama, 2011; Kurylyk et al., 2013, 2014a; Taylor and Stefan, 2009) as reviewed in detail by Kurylyk et al. (2014b). Previous studies have also noted groundwater warming in response to deforestation due to the removal of the forest canopy (e.g., Alexander, 2006; Guenther et al., 2014; Henriksen and Kirkhusmo, 2000; Steeves, 2004; Taniguchi et al., 1998). Others have observed subsurface warming following wildfires. Burn (1998) found that the mean annual surface temperature at a burned site in southern Yukon, Canada, was $0.6^{\circ} \mathrm{C}$ warmer than the surrounding surface thermal regime, and this surface thermal perturbation rapidly increased shallow subsurface temperatures.

In all cases (i.e., climate change, deforestation, and wildfires), the surface disturbance warms shallow aquifers by increasing the downward heat flux from the warming land surface. For example, climate change can influence surface thermal regimes and subsurface heat fluxes by altering convective energy fluxes from the lower atmosphere and causing increased net radiation at the ground surface (Jungqvist et al., 2014; Kurylyk et al., 2013; Mellander et al., 2007). The influence of wildfires or forest harvesting on surface thermal regimes can be complex. The removal of the forest canopy can decrease transpiration and thus increase the energy available to warm the land surface (Rouse, 1976). Lewis and Wang (1998) demonstrated that the majority of surface and subsurface warming caused by wildfires at sites in British Columbia and Yukon, Canada, could be attributed to decreased transpiration. Decreased surface albedo and consequent increased net radiation at the land surface can also arise due to wildfires (Yoshikawa et al., 2003). The increase in surface temperature as a result of a land cover disturbance will depend on the original vegetative state, climate, ground ice conditions, and potential for vegetative regrowth (Liljedahl et al., 2007). In the case of a wildfire or in post-harvest tree planting, the vegetation may eventually regenerate, and the surface-energy balance and temperature may return to the pre-fire conditions (Burn, 1998).

Kurylyk et al. (2013, 2014a) demonstrated that shallow groundwater warming may eventually exceed the magnitude of surface water warming and thus stream temperature models that do not consider this phenomenon may be overly conservative. The empirical method proposed by Kurylyk et al. (2013) for estimating the magnitude of groundwater warming requires measured land surface temperature and depth-dependent groundwater temperature for model calibration, but there is often a paucity of such temperature data available at the catchment scale. Also, the numerical modeling described by Kurylyk et al. (2014a) is time intensive and requires considerable data for model parameterization. These previous approaches for quantifying groundwater warming are site specific, and thus the results are not generally transferable to existing models that are used to investigate stream thermal regimes.

The intent of this study is to provide alternative, parsimonious approaches for investigating factors that influence the timing and magnitude of groundwater temperature changes in response to climate change or land cover disturbances. The specific objectives of this paper are twofold:

1. derive easy-to-use formulae to estimate the thermal sensitivity of groundwater to different surface-temperature changes (e.g., seasonal cycle or multi-decadal increases);

2. demonstrate how these formulae can be utilized to estimate how the groundwater thermal sensitivity in idealized environments is influenced by the depth, groundwater recharge rate, and subsurface thermal properties.

The illustrative examples (objective 2) will also be used to demonstrate the difference in the subsurface thermal response to short-term (seasonal) and long-term (multidecadal) surface-temperature trends. Consequently, the results will be employed to highlight the limitations of employing empirical stream temperature models with constant coefficients obtained from short-term temperature records to project future stream warming. The results will also demonstrate how stream temperature models can be improved to accommodate groundwater warming using these simple approaches.

\section{Methods}

There are several approaches for estimating future groundwater temperature warming in response to changes in land cover or climate. It is well known that mean annual ground surface temperature and shallow groundwater temperature are approximately equal to mean annual air temperature plus 
some thermal offset (e.g., $1-4^{\circ} \mathrm{C}$ ) due to the insulating effect of snow (Zhang, 2005). Meisner et al. (1988) employed this knowledge to estimate future groundwater temperatures by adding a thermal offset to projections of future mean annual air temperature. The approach employed by Meisner et al. (1988) utilized mean annual surface temperature as a proxy for groundwater temperature and thus implicitly assumed that the aquifer and ground surface are always in thermal equilibrium. The equilibrium assumption was also invoked in the empirical function described by Kurylyk et al. (2013). Such an approach does not consider the lag that occurs between an increase in surface temperature and its subsequent realization at some depth within the subsurface (Lesperance et al., 2010) and thus is only valid for very shallow groundwater (e.g., $<5 \mathrm{~m}$ ) or for long timescales.

Analytical solutions to subsurface heat transfer differential equations can also be applied to estimate the influence of future climate change on groundwater temperature (Gunawardhana and Kazama, 2011; Kurylyk and MacQuarrie, 2014; Menberg et al., 2014), although these approaches have most often been applied for deeper aquifers. Finally, numerical models of groundwater flow and coupled heat transport can be employed to investigate the thermal evolution of aquifers due to warming surface temperatures (e.g., Gunawardhana and Kazama, 2012; Kurylyk et al., 2014a). These numerical models are more flexible and can accommodate multidimensional groundwater flow and heat transport and inhomogeneities in subsurface thermal properties, but they require extensive subsurface field data for model parameterization.

Herein, we employ analytical solutions to a onedimensional, unsteady heat transport equation to estimate subsurface-temperature evolution due to climate change, permanent land cover changes, and wildfires. These solutions are physically based and account for the lag in the thermal response of groundwater to surface-temperature changes. Also, unlike the solution employed by Taylor and Stefan (2009), these solutions accommodate the subsurface thermal effects of vertically moving groundwater. The solutions provide an indication of expected groundwater warming due to climate or land cover changes, and the results can be incorporated into stream temperature models in the absence of site-specific hydrogeological modeling. These simple analytical solutions are particularly useful for performing parsimonious analyses when there is a paucity of subsurface data (e.g., hydraulic conductivity distribution) for parameterizing groundwater flow and energy transport models. Also, analytical solutions limit the degrees of freedom for a particular analysis and thus facilitate a comprehensive evaluation of possible interactions between model inputs and resultant solutions. As we demonstrate, the forms of these solutions can also be utilized to derive mathematical expressions for groundwater thermal sensitivity to surface-temperature perturbations. The analytical solutions discussed in this paper invoke assump- tions, and the limitations arising from these assumptions will be discussed later.

\subsection{Advection-diffusion heat transport equation}

Shallow subsurface heat transfer occurs primarily due to heat conduction and heat advection (Domenico and Schwartz, 1990), although the latent heat released or absorbed during pore water freeze-thaw can also be important in cold regions (Kurylyk et al., 2014b). The one-dimensional, transient conduction-advection equation for subsurface heat transport is (Stallman, 1963)

$\lambda \frac{\partial^{2} T}{\partial z^{2}}-q c_{\mathrm{w}} \rho_{\mathrm{w}} \frac{\partial T}{\partial z}=c \rho \frac{\partial T}{\partial t}$,

where $\lambda$ is the bulk thermal conductivity of the soil-water matrix $\left(\mathrm{W} \mathrm{m}^{-1}{ }^{\circ} \mathrm{C}^{-1}\right), T$ is the temperature at any point in space or time $\left({ }^{\circ} \mathrm{C}\right), z$ is the depth below the surface $(\mathrm{m}$; down is positive and the land surface occurs at $z=0), q$ is the vertical Darcy flux ( $\mathrm{m} \mathrm{s}^{-1}$; down is positive), $c_{\mathrm{W}} \rho_{\mathrm{W}}$ is the volumetric heat capacity of pure water $\left(4.18 \times 10^{6} \mathrm{~J} \mathrm{~m}^{-3}{ }^{\circ} \mathrm{C}^{-1}\right.$; Bonan, 2008), $t$ is time (s), and $c \rho$ is the bulk volumetric heat capacity of the soil-water matrix $\left(\mathrm{J} \mathrm{m}^{-3}{ }^{\circ} \mathrm{C}^{-1}\right)$. The first term on the left of Eq. (1) represents the divergence of the conductive flux, the second term on the left represents the divergence of the advective flux, and the term on the right represents the rate of change of thermal storage. Subsurface heat transport phenomena and the physical meaning of the terms in Eq. (1) are reviewed in more detail by Rau et al. (2014) and Kurylyk et al. (2014b).

Equation (1) is often rewritten in the form (Carslaw and Jaeger, 1959)

$D \frac{\partial^{2} T}{\partial z^{2}}-U \frac{\partial T}{\partial z}=\frac{\partial T}{\partial t}$,

where $D$ is the bulk thermal diffusivity (thermal conductivity divided by heat capacity) of the soil-water matrix $\left(\mathrm{m}^{2} \mathrm{~s}^{-1}\right)$, and $U$ is the velocity of a thermal plume due only to heat advection $\left(\mathrm{m} \mathrm{s}^{-1}\right)$. Even in the absence of conduction, the thermal plume will not migrate at the same rate as the Darcy velocity due to differences in the heat capacities of water and the medium (Markle and Schincariol, 2007; Luce et al., 2013). An expression for $U$ can be obtained via a comparison of Eqs. (1) and (2)

$U=q \frac{c_{\mathrm{W}} \rho_{\mathrm{W}}}{c \rho}$.

Often an effective thermal diffusivity term, which accounts for the combined thermal homogenizing effects of heat diffusion and heat dispersion, is utilized in place of the bulk thermal diffusivity term $D$ in Eq. (2). However, it is still common to ignore the subsurface thermal effects of dispersion, which are often minimal in comparison to heat conduction (Kurylyk et al., 2014b; Rau et al., 2014). Equation (2) represents 
Table 1. Details regarding the four analytical solutions employed in this study.

\begin{tabular}{|c|c|c|c|c|}
\hline $\begin{array}{l}\text { Solution } \\
\text { ID }\end{array}$ & $\begin{array}{l}\text { Equation } \\
\text { number }\end{array}$ & Timescale & $\begin{array}{l}\text { Surface } \\
\text { temperature* }\end{array}$ & $\begin{array}{l}\text { Solution } \\
\text { reference }\end{array}$ \\
\hline 1 & $(5)$ & Seasonal or diel & Sinusoidal & Stallman (1965) \\
\hline 2 & (11) & Multi-decadal & Step change(s) & Menberg et al. (2014) \\
\hline 3 & (13) & Multi-decadal & Linear increase & Taniguchi et al. (1999b) \\
\hline 4 & (15) & Multi-decadal & Exponential increase & Kurylyk and MacQuarrie (2014) \\
\hline
\end{tabular}

* For boundary conditions, see Eqs. (4), (10), (12), and (14).

vertical subsurface heat transport processes and accounts for the thermal effects of heat conduction induced by a thermal gradient and heat advection induced by groundwater flow. Analytical solutions to this equation can be developed and applied to consider inter-relationships between groundwater flow, surface-temperature changes, and subsurface thermal regimes. We consider four analytical solutions to Eq. (2) (Table 1) that vary based on the nature of the surface boundary condition. These are discussed in subsequent sections.

\subsection{Analytical solution 1: harmonic surface-temperature changes}

The diel or seasonal land surface-temperature cycle can be approximated with a harmonic function. Suzuki (1960) derived an analytical solution to Eq. (2) subject to a sinusoidal surface-temperature boundary condition:

Boundary condition: $T(z=0, t)=T_{\mathrm{m}}+A \sin \left(\frac{2 \pi t}{p}-\varphi\right)$,

Solution : $T(z, t)=T_{\mathrm{m}}+A \exp (-\mathrm{d} z) \sin \left(\frac{2 \pi t}{p}-\varphi-L z\right)$,

where $A$ is the amplitude of the harmonic surfacetemperature cycle $\left({ }^{\circ} \mathrm{C}\right), T_{\mathrm{m}}$ is the mean surface temperature $\left({ }^{\circ} \mathrm{C}\right), p$ is the period of the surface-temperature cycle $(\mathrm{s}), \varphi$ is a phase shift to align the timing of the surface-temperature signal with the sinusoid (rad), $d$ is a thermal damping term $\left(\mathrm{m}^{-1}\right)$, and $L$ is a lag term $\left(\mathrm{m}^{-1}\right)$. Equation (5) thus states that the harmonic temperature signal at the surface retains its period within the subsurface but is exponentially damped and linearly lagged with depth. Stallman (1965) demonstrated that the exact expressions for $d$ and $L$ are

$d=\left[\left\{\left(\frac{\pi}{D p}\right)^{2}+0.25\left(\frac{U}{2 D}\right)^{4}\right\}^{0.5}+0.5\left(\frac{U}{2 D}\right)^{2}\right]^{0.5}-\frac{U}{2 D}$
$L=\left[\left\{\left(\frac{\pi}{D p}\right)^{2}+0.25\left(\frac{U}{2 D}\right)^{4}\right\}^{0.5}-0.5\left(\frac{U}{2 D}\right)^{2}\right]^{0.5}$

Equations (5) to (7) are generally collectively referred to as Stallman's equation. No initial conditions are presented for the solution of Stallman (1965) as it assumes that the boundary condition has been repeating the harmonic cycle indefi- nitely. This solution also depends on a lower boundary condition $\left(T=T_{\mathrm{m}}\right)$ at infinite depth. Various forms of this solution have been applied/inverted to infer rates of groundwater flow due to subsurface temperature-time series arising from daily or seasonal harmonic variations in surface temperature (e.g., Anderson, 2005; Hatch et al., 2006; Rau et al., 2014). Here, we employ the solution of Stallman (1965) in a forward manner to demonstrate why seasonal changes in air and surface temperature are not manifested in subsurface thermal regimes below certain depths, and thus why groundwaterdominated streams and rivers exhibit low thermal sensitivity to seasonal weather variability. In particular, we consider the ratio of the amplitude of the seasonal groundwater temperature cycle at any arbitrary depth to the amplitude of the surface-temperature boundary condition. This dimensionless parameter, herein referred to as the exponential damping factor $\Omega$, can be obtained from Eqs. (4) and (5)

$\Omega=\frac{\text { Amplitude at depth }=z}{\text { Amplitude at depth }=0}=\frac{A \exp (-\mathrm{d} z)}{A}=\exp (-\mathrm{d} z)$.

\subsection{Analytical solution 2: step change(s) in surface temperature due to land cover disturbances}

Taniguchi et al. (1999a) demonstrated how an analytical solution presented by Carslaw and Jaeger (1959) could be modified to calculate the groundwater warming arising from a sudden and permanent increase in surface temperature. This increase in surface temperature could arise due to rapid and large-scale timber harvesting or other changes in land use. Menberg et al. (2014) proposed that superposition principles could be employed to modify the solution by Taniguchi et al. (1999a) by considering a series of shifts in the surfacetemperature boundary condition. Herein we employ the technique by Menberg et al. (2014) and consider up to two sequential shifts in the boundary condition. The first shift, which warms the surface temperature, occurs at $t=0$, and after a period of time $\left(t=t_{1}\right)$, the surface temperature returns to its value prior to the initial warming $\left(T_{0}\right)$. Such a boundary condition could approximate the sudden temporary increase in mean annual surface temperature due to a wildfire and the subsequent return to pre-fire surface temperatures due to vegetation regrowth (Burn, 1998). Alternatively, this boundary condition could represent the effect of clearcutting followed by industrial tree planting. The subsequent surface cooling 
due to gradual vegetative regrowth could also be represented with a series of shorter less intense cooling phases, but for the illustrative examples in the present study we assume one warming shift followed by one cooling shift of equal magnitude:

$$
\begin{aligned}
& \text { Initial conditions : } T(z, t=0)=T_{0}, \\
& \text { Boundary condition : } T(z=0, t)=\left\{\begin{array}{ll}
T_{0}+\Delta T & \text { for } 0<t<t_{1} \\
T_{0} & \text { for } t \geq t_{1}
\end{array}\right\}, \\
& \text { Solution : } T(z, t) \\
& =\left[\begin{array}{ll}
T_{0}+\frac{\Delta T}{2}\left\{\operatorname{erfc}\left(\frac{z-U t}{2 \sqrt{D t}}\right)+\exp \left(\frac{U z}{D}\right) \operatorname{erfc}\left(\frac{z+U t}{2 \sqrt{D t}}\right)\right\} & \text { for } 0 \leq t<t_{1} \\
T_{0}+\frac{\Delta T}{2}\left\{\operatorname{erfc}\left(\frac{z-U t}{2 \sqrt{D t}}\right)+\exp \left(\frac{U z}{D}\right) \operatorname{erfc}\left(\frac{z+U t}{2 \sqrt{D t}}\right)\right\} & \\
-\frac{\Delta T}{2}\left\{\operatorname{erfc}\left(\frac{z-U\left(t-t_{1}\right)}{\left.2 \sqrt{D\left(t-t_{1}\right.}\right)}\right)+\exp \left(\frac{U z}{D}\right) \operatorname{erfc}\left(\frac{z+U\left(t-t_{1}\right)}{\left.2 \sqrt{D\left(t-t_{1}\right.}\right)}\right)\right\} & \text { for } t \geq t_{1}
\end{array}\right],
\end{aligned}
$$

where $T_{0}$ is the uniform initial temperature $\left({ }^{\circ} \mathrm{C}\right), \Delta T$ is the magnitude of the surface-temperature shift $\left({ }^{\circ} \mathrm{C}\right)$, erfc is the complementary error function, and $t_{1}$ is the duration of the period characterized by warmer surface temperatures (s).

This solution and the remaining three solutions presented later also require a lower boundary condition at infinite depth ( $T=T_{0}$ ). Equation (11) can be employed to consider the subsurface warming due to a permanent step change in surface temperature (i.e., no subsequent cooling due to vegetative regrowth) by setting $t_{1}$ to infinity. In this case, only the first line on the right-hand side of Eq. (11) is retained. Even when $t_{1}$ is set to infinity, Eq. (11) differs slightly from the solution presented by Taniguchi et al. (1999a) because uniform initial temperatures are assumed in the present study (Eq. 9). These initial conditions ignore the influence of the geothermal gradient and imply that the recent climate has been relatively stable. We employ these simplifying assumptions given that we are primarily interested in shallower depths (e.g., $<25 \mathrm{~m}$ ) where the influence of the geothermal gradient is not as important. Also, the boundary conditions for this solution and the following solutions do not include seasonal temperature variations. Thus, these solutions are valid for predicting the evolution of mean annual groundwater temperature.

\subsection{Analytical solution 3: linear increase in surface temperature due to climate change}

Carslaw and Jaeger (1959) also presented an analytical solution to Eq. (2) subject to linearly increasing surface temperature. This solution was later adapted by Taniguchi et al. (1999b) and applied to study groundwater temperature evolution due to climate change. Herein, the analytical solution is presented in a slightly simpler form as thermally uniform initial conditions are assumed (i.e., initial conditions are given by Eq. 9):

Boundary condition: $T(z=0, t)=T_{0}+\beta t$,

$$
\begin{aligned}
& \text { Solution :T(z,t)=T0 }+\frac{\beta}{2 U}\left[(U t-z) \times \operatorname{erfc}\left(\frac{z-U t}{2 \sqrt{D t}}\right)\right. \\
& \left.+(U t+z) \exp \left(\frac{U z}{D}\right) \operatorname{erfc}\left(\frac{z+U t}{2 \sqrt{D t}}\right)\right] \text {, }
\end{aligned}
$$

where $\beta$ is the rate of the increase in surface temperature $\left({ }^{\circ} \mathrm{Cs}^{-1}\right)$.

Equation (13) has been applied in an inverse manner to consider the complex relationships between past surfacetemperature changes, groundwater flow, and measured subsurface temperature-depth profiles (e.g., Miyakoshi et al., 2003; Taniguchi et al., 1999b; Uchida and Hayashi, 2005). It has also been applied to forward model future groundwater temperature evolution due to projected climate change $(\mathrm{Gu}-$ nawardhana and Kazama, 2011). Herein, the surface boundary condition (Eq. 12) is fitted to mean annual air temperature trends produced by climate models. Because it is surface temperature, rather than air temperature, that drives shallow subsurface thermal regimes, this approach tacitly assumes that mean annual surface and air temperature trends are coupled. Thus, air temperature is being used as a proxy for surface temperature in this approach. Snowpack evolution may invalidate this assumption (Mellander et al., 2007), and thus it is best employed where snowpack effects are minimal. Snowpack evolution would typically retard the rate of groundwater warming (Kurylyk et al., 2013).

\subsection{Analytical solution 4: exponential increase in surface temperature due to climate change}

It may be inappropriate to assume a linear surface temperature rise as in Eq. (13), because many climate scenarios suggest that the rate of climate warming will increase over time. Figure 2 presents the globally averaged IPCC (2007) multimodel air temperature projections for two different emission scenarios. The global air temperature series projected for the conservative emission scenario B1 is much better represented by a linear function than the air temperature series for the aggressive A2 emission scenario, which exhibits significant concavity.

In such cases, the boundary condition would be better represented as an exponential function (Kurylyk and MacQuarrie, 2014). The solution presented here is simpler than the original form given that the initial conditions are assumed to be thermally uniform (initial conditions $=$ Eq. 9):

Boundary condition : $T(z=0, t)=T_{1}+b \exp (c t)$, 


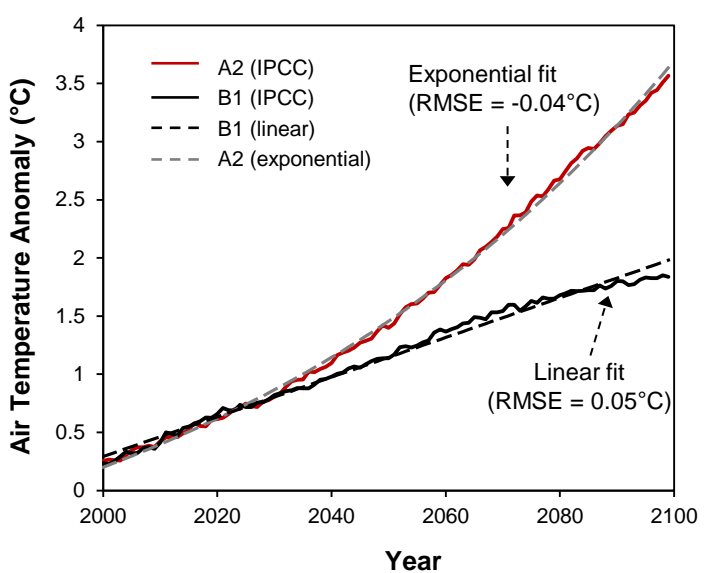

Figure 2. IPCC multi-model globally averaged air temperature anomaly projections for the twenty-first century relative to the air temperature data for 1980-1999 for emission scenarios B1 and A2 (data from, IPCC, 2007). Details concerning the exponential and linear fits to the IPCC projections are given in Sect. 3.3.1. Modified from Kurylyk and MacQuarrie (2014).

Solution $: T(z, t)=T_{0}+\frac{\left(T_{1}-T_{0}\right)}{2}$

$$
\begin{aligned}
& \left\{\begin{array}{l}
\operatorname{erfc}\left(\frac{z}{2 \sqrt{D t}}-\frac{U}{2} \sqrt{\frac{t}{D}}\right) \\
+\exp \left(\frac{U z}{D}\right) \operatorname{erfc}\left(\frac{z}{2 \sqrt{D t}}+\frac{U}{2} \sqrt{\frac{t}{D}}\right)
\end{array}\right\} \\
& +\frac{b}{2} \exp \left(\frac{U z}{2 D}+c t\right) \\
& \left\{\begin{array}{c}
\exp \left(-z \sqrt{U^{2} / 4 D^{2}+c / D}\right) \operatorname{erfc}\left(\frac{z}{2 \sqrt{D t}}-\sqrt{\left(\frac{U^{2}}{4 D}+c\right) t}\right) \\
+\exp \left(z \sqrt{U^{2} / 4 D^{2}+c t / D}\right) \operatorname{erfc}\left(\frac{z}{2 \sqrt{D t}}+\sqrt{\left(\frac{U^{2}}{4 D}+c\right) t}\right)
\end{array}\right\},
\end{aligned}
$$

where $T_{1}\left({ }^{\circ} \mathrm{C}\right), b\left({ }^{\circ} \mathrm{C}\right)$, and $c\left(\mathrm{~s}^{-1}\right)$ are parameters for the surface-temperature boundary condition which can be fitted to climate model projections. Note that $T_{1}+b$ must equal $T_{0}$ for the boundary and initial conditions to converge at $t=0$, $z=0$. The original initial condition function proposed by Kurylyk and MacQuarrie (2014) superimposed linear and exponential functions, and thus the more complex form of the solution can also be applied to forward model future climate change impacts on deeper subsurface-temperature profiles. These temperature profiles can deviate from the geothermal gradient due to groundwater flow or recent surfacetemperature changes (Ferguson and Woodbury, 2005; Reiter, 2005). The alternate forms of the boundary conditions presented in Eqs. (10), (12), and (14) are illustrated in Fig. 3. Each of the listed analytical solutions to the one-dimensional, transient advection-diffusion equation is provided in Table 1 with details to highlight their differences.

\subsection{Effective aquifer depth}

The analytical solutions discussed above can be utilized to estimate the influence of surface warming at any desired

\section{(a) Permanent step increase in surface temperature (Eq. 10)}

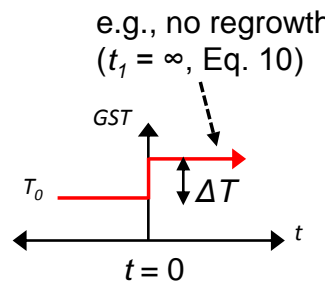

(c) Linearly increasing surface temperature (Eq. 12)

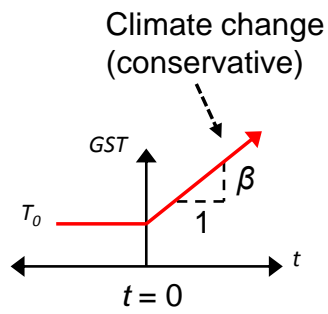

\section{(b) Temporary step increase in surface temperature (Eq. 10)}

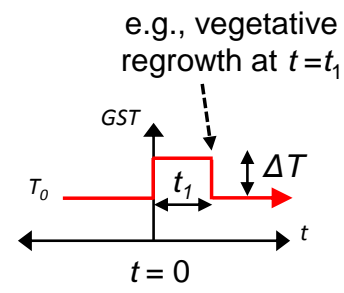

(d) Exponentially increasing surface temperature (Eq. 14)

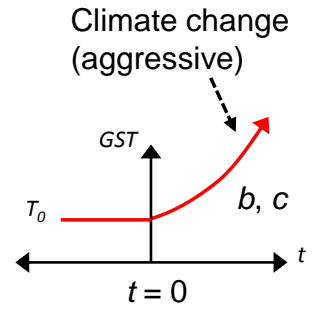

Figure 3. (a-b) The boundary conditions for ground surfacetemperature (GST) disturbances due to land cover changes. Both (a) and (b) represent the boundary condition given in Eq. (10). The difference between these is the duration of the period of warm surface temperatures $\left(t_{1}=\infty\right.$ in a). (c-d) The boundary conditions for GST due to long-term climate change for conservative (linear; Eq. 12) and aggressive (exponential; Eq. 14) climate scenarios.

depth. However, groundwater discharge to streams is sourced from different depths within the aquifer depending on the recharge location and the subsurface flow paths (Fig. 4a). Because the water table slope in unconfined aquifers is typically subdued in comparison to the land surface slope (Domenico and Schwartz, 1990), soil water that recharges the aquifer further upslope typically has a longer residence time and reaches greater depths relative to the land surface than soil water recharging the aquifer close to the discharge point. Groundwater flow in aquifers is often conceptualized as occurring in different "flow channels" or "flow tubes" (Domenico and Schwartz, 1990), and groundwater discharge is a thermal and hydraulic mixture of different groundwater flow channels coming from different depths and converging at the discharge point (Hoehn and Cirpka, 2006 and Fig. 4). Thus, when employing one-dimensional solutions to investigate the thermal evolution of groundwater discharge to streams and rivers, an effective depth $z_{\text {eff }}(\mathrm{m})$ must be considered that represents the bulk aquifer depth (i.e., accounting for all discharging groundwater flow channels) as a single point within the subsurface (Fig. 4). As a first estimate, this depth may be taken as the average unsaturated zone thickness. Figure $4 \mathrm{~b}$ shows the conceptual model employed in this 


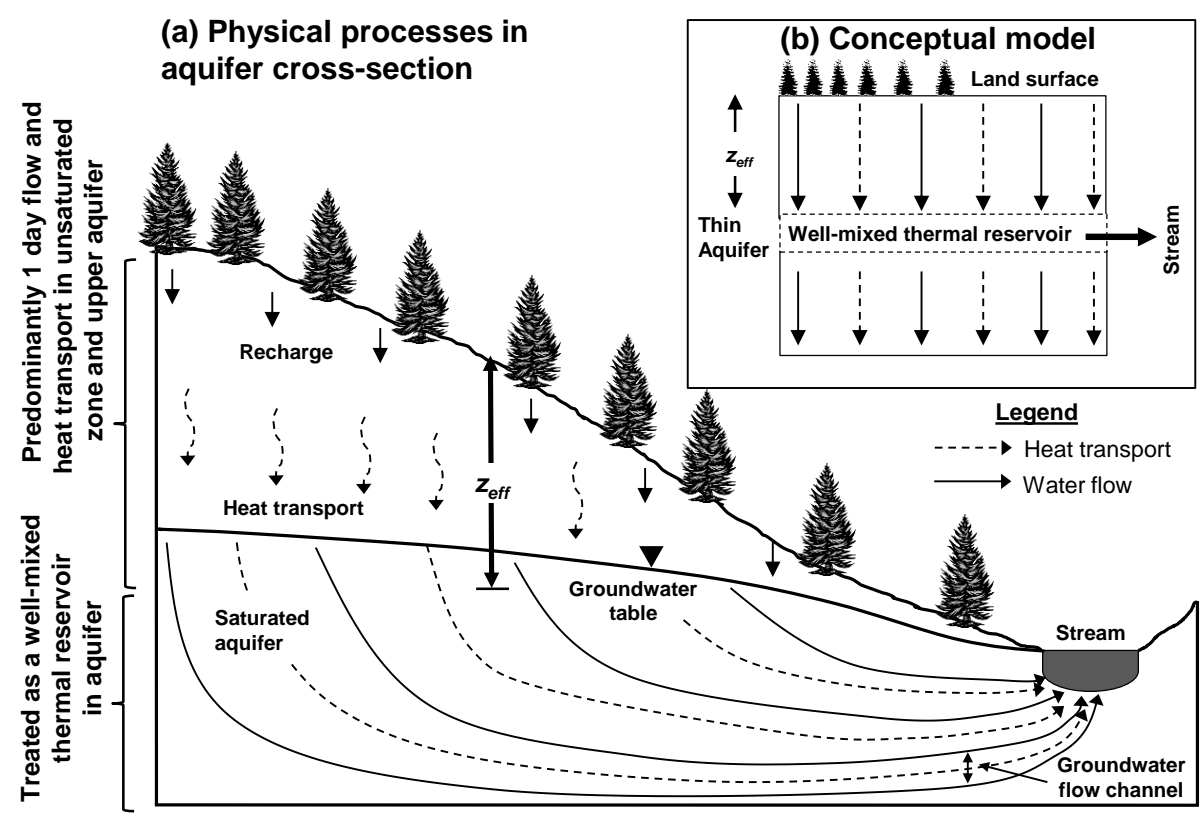

Figure 4. (a) Groundwater flow and heat transport in a two-dimensional cross section of an aquifer-stream system. (b) Conceptual model of the physical processes shown in (a). Dashed arrows indicate heat transport, and solid arrows indicate water flow.

study. Above the effective depth, heat transport and water flow is assumed to be predominantly vertical as is often the case within the unsaturated zone, in overlying aquitards, or even in the upper portion of the aquifer (e.g., Kurylyk et al., 2014b). Within the aquifer (located at the effective depth), groundwater discharges horizontally towards a stream, and horizontal conductive heat transport is assumed to be negligible due to the relatively low horizontal thermal gradients in this zone. Heat advection and associated thermal dispersion near the discharge point is assumed to dominate vertical heat transfer and thus create a thermally uniform zone. Thus, the aquifer is treated as a thin, horizontally well-mixed thermal reservoir discharging to a surface water body (Fig. 4b). This approach is somewhat analogous to how contaminant hydrogeology studies have considered aquifers to be well-mixed reservoirs with respect to solute concentrations (e.g., Gelhar and Wilson, 1974). Vertical heat transfer continues below the aquifer (Fig. 4b). Limitations of this approach are discussed later.

\subsection{Groundwater thermal sensitivity to long-term surface-temperature perturbations}

Groundwater thermal sensitivity is herein defined as the change in groundwater temperature at some depth and time divided by the driving change in surface $(z=0)$ temperature at the same time. For example, if the surface temperature increases by $2{ }^{\circ} \mathrm{C}$ and the groundwater temperature has only increased by $1.4^{\circ} \mathrm{C}$ at that same time, then the groundwater thermal sensitivity is $0.7\left(1.4{ }^{\circ} \mathrm{C} / 2^{\circ} \mathrm{C}\right)$. The temperature changes at the surface and in the aquifer are measured with respect to the initial temperatures at those locations. This definition for groundwater thermal sensitivity $S\left({ }^{\circ} \mathrm{C}^{\circ} \mathrm{C}^{-1}\right)$ can be expressed in the following manner:

$$
\begin{aligned}
S(z, t) & =\frac{\Delta \text { Subsurface Temp. }}{\Delta \text { Surface Temp. }} \\
& =\frac{T(z, t)-T(z, t=0)}{T(z=0, t)-T(z=0, t=0)} .
\end{aligned}
$$

The groundwater thermal sensitivity is the analog to the stream thermal sensitivity defined by Kelleher et al. (2012), although the temperature changes are measured on a longer timescale for groundwater (e.g., multi-decadal vs. seasonal). Equation (16) represents the thermal sensitivity at any arbitrary depth within the aquifer. The bulk (i.e., the entire portion of the aquifer discharging to the stream or river) groundwater thermal sensitivity in Eq. (16) can be found by replacing $z$ with $z_{\text {eff }}$.

\subsubsection{Groundwater thermal sensitivity to a step increase in surface temperature (land cover disturbance)}

The groundwater thermal sensitivity $S_{\mathrm{s}}$ (subscript denotes nature of boundary condition) to a step increase in surface temperature occurring at $t=0$ followed by subsequent surface cooling at $t=t_{1}$ can be found by inserting Eqs. (9), (10), and (11) into Eq. (16) 
$S_{\mathrm{S}}(z, t)$

$=\left[\begin{array}{ll}\frac{1}{2}\left\{\operatorname{erfc}\left(\frac{z-U t}{2 \sqrt{D t}}\right)+\exp \left(\frac{U z}{D}\right) \operatorname{erfc}\left(\frac{z+U t}{2 \sqrt{D t}}\right)\right\} & \text { for } 0 \leq t<t_{1} \\ \frac{1}{2}\left\{\operatorname{erfc}\left(\frac{z-U t}{2 \sqrt{D t}}\right)+\exp \left(\frac{U z}{D}\right) \operatorname{erfc}\left(\frac{z+U t}{2 \sqrt{D t}}\right)\right\} & \\ -\frac{1}{2}\left\{\operatorname{erfc}\left(\frac{z-U\left(t-t_{1}\right)}{2 \sqrt{D\left(t-t_{1}\right)}}\right)+\exp \left(\frac{U z}{D}\right) \operatorname{erfc}\left(\frac{z+U\left(t-t_{1}\right)}{\left.2 \sqrt{D\left(t-t_{1}\right.}\right)}\right)\right\} & \text { for } t \geq t_{1}\end{array}\right]$

In Eq. (17), sensitivities for all times greater than $t_{1}$ are calculated with respect to the initial temperature perturbation $\Delta T$. Interestingly, the groundwater thermal sensitivity is not dependent on the magnitude of the step change in surface temperature $\Delta T$ or the initial temperature $T_{0}$, provided that the initial temperature is uniform. Equation (17) has the same form as the well-known solute transport analytical solution proposed by Ogata and Banks (1961) to calculate normalized solute concentrations.

As in the case of Eq. (11), Eq. (17) can be simplified to represent the influence of a permanent step increase (i.e., no subsequent cooling) in surface temperature by setting $t_{1}$ to infinity and only considering the first line on the right-hand side of the equation.

\subsubsection{Groundwater thermal sensitivity to gradual increases in surface temperature (climate change)}

Equation (16) can also be applied to obtain an expression for the groundwater thermal sensitivity $S_{\mathrm{L}}\left({ }^{\circ} \mathrm{C}^{\circ} \mathrm{C}^{-1}\right)$ due to a linear increase in the surface-temperature boundary condition by inserting Eqs. (9), (12), and (13) into Eq. (16) and simplifying:

$$
\begin{aligned}
S_{\mathrm{L}}(z, t) & =\frac{1}{2 U t}\left[(U t-z) \times \operatorname{erfc}\left(\frac{z-U t}{2 \sqrt{D t}}\right)\right. \\
& \left.+(U t+z) \exp \left(\frac{U z}{D}\right) \operatorname{erfc}\left(\frac{z+U t}{2 \sqrt{D t}}\right)\right] .
\end{aligned}
$$

Thus, $S_{\mathrm{L}}$ is independent of the initial temperature $T_{0}$ and the rate of surface warming $\beta$.

The groundwater thermal sensitivity $S_{\mathrm{E}}\left({ }^{\circ} \mathrm{C}^{\circ} \mathrm{C}^{-1}\right)$ to an exponentially increasing surface temperature can be obtained by inserting Eqs. (9), (14), and (15) into Eq. (16). The resultant solution can be further simplified by canceling terms and by remembering that $T_{0}$ is the sum of $T_{1}$ and $b$ :

$$
\begin{aligned}
S_{\mathrm{E}}(z, t) & =\frac{\left(T_{1}-T_{0}\right)}{2 b\{\exp (c t)-1\}} \\
& \left\{\begin{array}{l}
\operatorname{erfc}\left(\frac{z}{2 \sqrt{D t}}-\frac{U}{2} \sqrt{\frac{t}{D}}\right) \\
+\exp \left(\frac{U z}{D}\right) \operatorname{erfc}\left(\frac{z}{2 \sqrt{D t}}+\frac{U}{2} \sqrt{\left.\frac{t}{D}\right)}\right\}
\end{array}\right. \\
& +\frac{1}{2 \exp (c t)-2} \exp \left(\frac{U z}{2 D}+c t\right) \\
& \left\{\begin{array}{l}
\exp \left(-z \sqrt{U^{2} / 4 D^{2}+c / D}\right) \operatorname{erfc}\left(\frac{z}{2 \sqrt{D t}}-\sqrt{\left(\frac{U^{2}}{4 D}+c\right) t}\right) \\
+\exp \left(z \sqrt{U^{2} / 4 D^{2}+c / D}\right) \operatorname{erfc}\left(\frac{z}{2 \sqrt{D t}}+\sqrt{\left(\frac{U^{2}}{4 D}+c\right) t}\right)
\end{array}\right\} .
\end{aligned}
$$

\begin{tabular}{|c|c|c|c|}
\hline $\begin{array}{l}\text { Saturation } \\
\left(\mathrm{vol} \mathrm{vol}^{-1}\right)\end{array}$ & $\begin{array}{c}\text { Thermal } \\
\text { conductivity } \lambda \\
\left(\mathrm{W} \mathrm{m}^{-1}{ }^{\circ} \mathrm{C}^{-1}\right)\end{array}$ & $\begin{array}{l}\text { Heat capacity } c \rho \\
\left(10^{6} \mathrm{~J} \mathrm{~m}^{-3}{ }^{\circ} \mathrm{C}^{-1}\right)\end{array}$ & $\begin{array}{c}\text { Thermal } \\
\text { diffusivity } D \\
\left(10^{-6} \mathrm{~m}^{2} \mathrm{~s}^{-1}\right)\end{array}$ \\
\hline \multicolumn{4}{|c|}{ Sandy soil $($ porosity $=0.4$ ) } \\
\hline 0 & 0.30 & 1.28 & 0.24 \\
\hline 0.5 & 1.80 & 2.12 & 0.85 \\
\hline 1.0 & 2.20 & 2.96 & 0.74 \\
\hline \multicolumn{4}{|c|}{ Clay soil $($ porosity $=0.4)$} \\
\hline 0 & 0.25 & 1.42 & 0.18 \\
\hline 0.5 & 1.18 & 2.25 & 0.53 \\
\hline 1.0 & 1.58 & 3.10 & 0.51 \\
\hline \multicolumn{4}{|c|}{ Peat soil $($ porosity $=0.8)$} \\
\hline 0 & 0.06 & 0.60 & 0.10 \\
\hline 0.5 & 0.29 & 2.23 & 0.13 \\
\hline 1.0 & 0.50 & 4.17 & 0.12 \\
\hline
\end{tabular}

A spreadsheet is included in the Supplement that facilitates the calculation of the results for each of the analytical so-
Table 2. Bulk thermal properties of some common soils and their dependence on saturation.*

* Data obtained from Monteith and Unsworth (2007).

lutions and groundwater thermal sensitivity equations. The user may vary input parameters such as depth, thermal properties, groundwater velocity, time, initial temperature, and the surface-temperature boundary conditions.

\subsection{Subsurface thermal properties}

These analytical solutions assume that subsurface thermal properties are homogeneous, but in reality the bulk thermal properties of unconsolidated soils depend on many factors, including the mineral constituents, porosity, total moisture saturation, and the pore water phase (Farouki, 1981; Kurylyk et al., 2014b). Water has a much higher thermal conductivity than air; thus, the saturated zone typically is characterized by a higher bulk thermal conductivity than the unsaturated zone (Oke, 1978). Despite the existence of subsurface thermal property heterogeneities, natural variability in soil thermal properties is orders of magnitude less than the natural variability in hydraulic properties (Domenico and Schwartz, 1990), and thus homogeneous assumptions are better justified for subsurface heat transport than for subsurface water flow. Table 2 lists the bulk thermal properties for unfrozen sand, clay, and peat at three water saturations (volume of soil water/pore volume). These values are used to represent the typical ranges of thermal conductivities experienced in common unconsolidated soils. The bulk thermal diffusivities of these soils do not vary significantly at pore water saturations above 0.5 . 
(a) Seasonal temperature ${ }^{22}$ depth profiles for each month

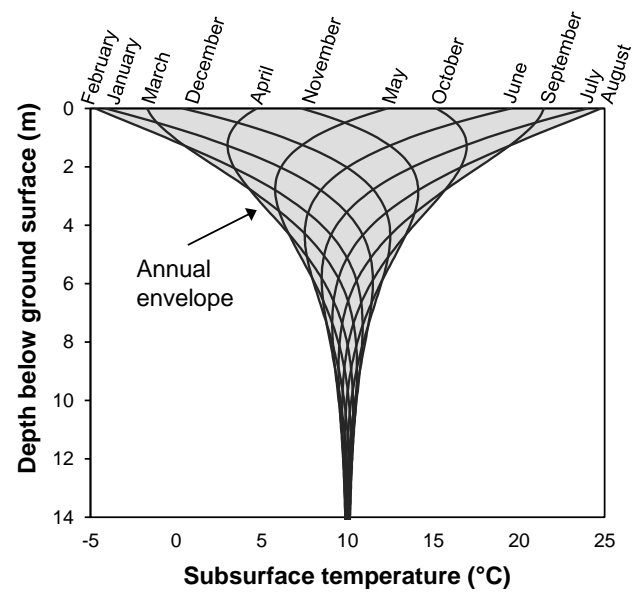

(b) Seasonal temperature ${ }^{22}$ time series at different depths

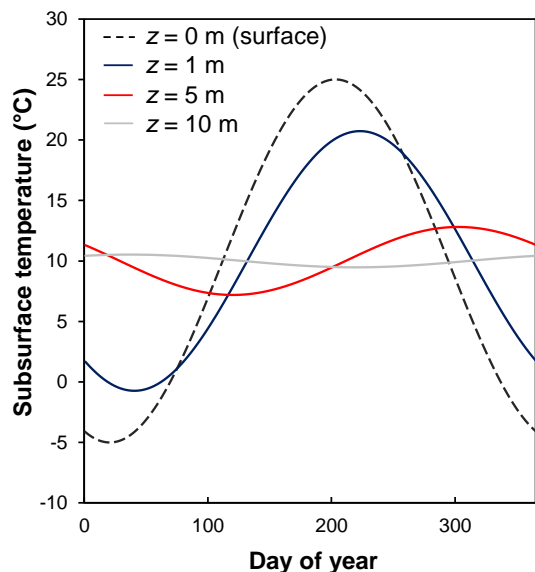

Figure 5. (a) Temperature-depth profiles for each month obtained from Stallman's equation (Eqs. 5-7) for homogeneous soil subject to harmonic seasonal surface-temperature variation. (b) Temperature-time series generated with Stallman's equation for depths of 0 , 1, 5, and $10 \mathrm{~m}$. In (a) and (b), the thermal properties for sand at $50 \%$ saturation (Table 2) were employed, and a recharge Darcy velocity of $0.2 \mathrm{~m} \mathrm{yr}{ }^{-1}$ was assumed. The boundary condition parameters $T_{\mathrm{m}}, A, \varphi$, and $p$ were assigned values of $10^{\circ} \mathrm{C}, 15^{\circ} \mathrm{C},-4.355$ radians, and $31536000 \mathrm{~s}$ (1 year), respectively, to represent typical surface-temperature conditions for a forested site in New Brunswick, Canada (e.g., Kurylyk et al., 2013).

\section{Results and discussion}

\subsection{Seasonal surface-temperature influences on groundwater temperature}

Stallman's equation (Eqs. 5-7) can be utilized to investigate how idealized subsurface environments respond to seasonal surface-temperature changes. Figure 5 shows temperaturedepth profiles for each month and temperature-time series for different depths in a soil column driven by a harmonic boundary condition at the surface (Eq. 4). The results were obtained from Eq. (5) for sandy soil (thermal properties; Table 2) and for a downwards Darcy velocity (i.e., recharge) of $0.2 \mathrm{~m} \mathrm{yr}^{-1}$. This recharge value was chosen as a representative basin groundwater recharge (Döll and Fiedler, 2008; Healy, 2010). Stallman's equation generally matches seasonal groundwater temperature data reasonably well in shallow subsurface environments, except in locations where snowpack can make the surface temperature non-sinusoidal and the subsurface thermal envelope (Fig. 5a) asymmetrical (Lapham, 1989). Regardless, Eq. (5) and Fig. 5 both demonstrate that the seasonal subsurface-temperature variability is exponentially attenuated with depth and is barely discernible beyond a certain depth (e.g., 10-14 m).

The exponential damping factor $\Omega$ is the ratio of the amplitude of the seasonal temperature cycle at an arbitrary depth $z$ to the amplitude of the seasonal surface-temperature cycle (Eq. 8). It is thus a measure of how the subsurface thermal regime responds to seasonal temperature variations, and it can be considered the seasonal counterpart to the groundwa- ter thermal sensitivities derived from the analytical solutions experiencing long-term surface-temperature variability. Figure 6 illustrates that the exponential damping factor (or seasonal thermal sensitivity) $\Omega$ for a given depth decreases for the discharge scenario (black series; Fig. 6) in comparison to the recharge scenario (dashed-blue series). In a discharge scenario, the upward advective flux is impeding the downward propagation of the surface-temperature signal, and thus the surface signal is more quickly attenuated.

Figure $6 \mathrm{a}-\mathrm{c}$ also indicate that the soil thermal properties greatly influence the subsurface thermal response to seasonal temperature variability. In particular, due to the significantly lower thermal diffusivity of partially saturated peat (Table 2), the surface-temperature signal is more quickly damped in the peat soil (Fig. 6c) in comparison to the results obtained for sand (Fig. 6a) and clay (Fig. 6b). However, in each of the nine scenarios presented in Fig. 6 , the $\Omega$ parameter is less than 0.2 (amplitude reduced by at least $80 \%$ ) when the depth is greater than $5 \mathrm{~m}$, which indicates that groundwater discharge does not have to be sourced from a very deep aquifer to decrease the stream thermal sensitivity to seasonal air temperature changes.

\subsection{Impacts of land cover disturbances on groundwater temperatures}

Beyond the depth of seasonal temperature fluctuations (Fig. 5), groundwater temperature will still be influenced by long-term surface-temperature perturbations. For instance, Fig. 7a (solid lines) shows the groundwater warming produced with Eq. (11) at different depths and for different soils 

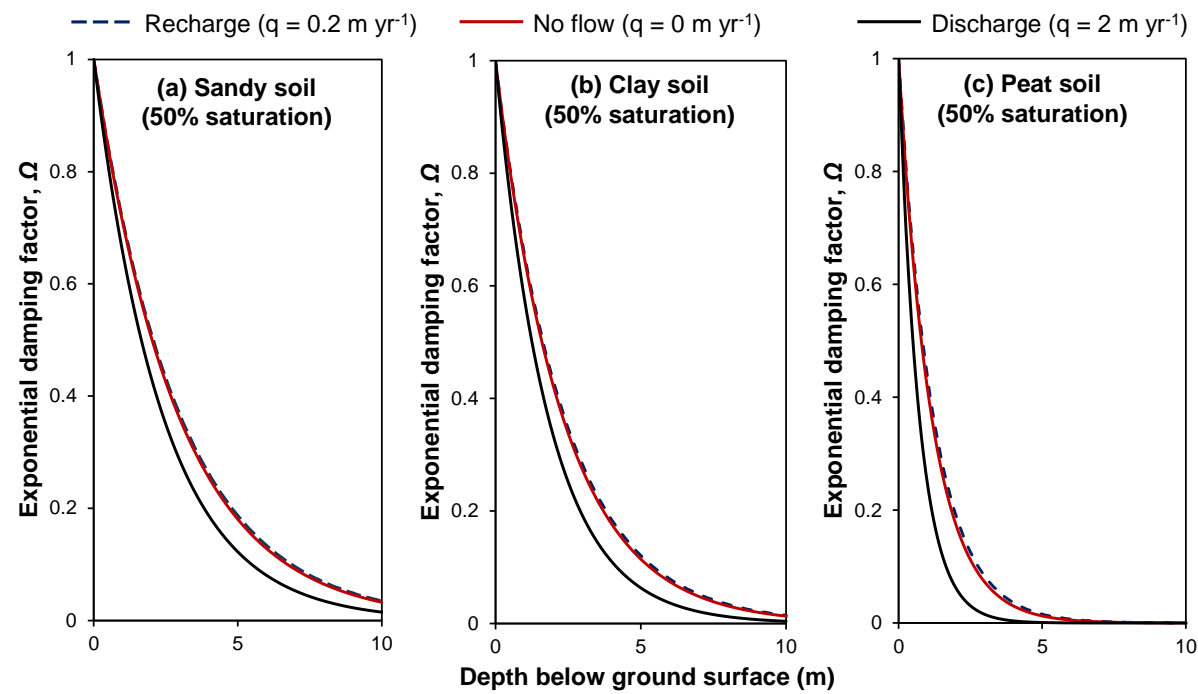

Figure 6. Exponential damping factor (seasonal temperature sensitivity) $\Omega$ (Eq. 8) vs. depth for (a) sandy soil, (b) clay soil, and (c) peat soil. The thermal properties were taken from Table 2 assuming a volumetric water saturation of $50 \%$. Results are presented for Darcy velocities of $0.2 \mathrm{~m} \mathrm{yr}^{-1}$ (recharge; downwards flow), 0 (conduction-dominated thermal regime), and $-2 \mathrm{~m} \mathrm{yr}^{-1}$ (discharge; upwards flow) and a period of 1 year. A higher discharge value was used in comparison to the recharge value given that discharge is typically concentrated over a smaller area than recharge.

(a) Groundwater warming due to $2^{\circ} \mathrm{C}$ step change(s) in surface temperature

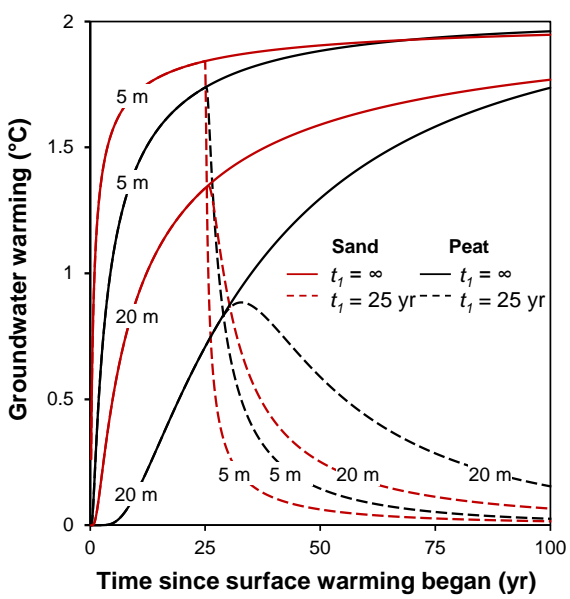

(b) Thermal sensitivity due to $2^{\circ} \mathrm{C}$ step change(s) in surface temperature

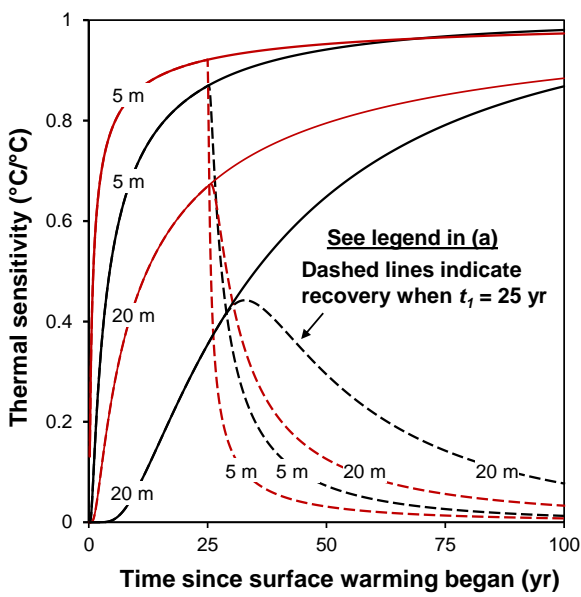

Figure 7. (a) Groundwater temperature warming due to a permanent (solid lines) or temporary (dashed lines) step increase in surface temperature vs. the time since the surface warming began. (b) Groundwater thermal sensitivity vs. time for each of the eight scenarios presented in (a). The results shown in (a) were obtained with Eq. (11) driven with the step boundary condition (Eq. 10), with $\Delta T=2{ }^{\circ} \mathrm{C}$ and $t_{1}=$ infinity (solid lines) or 25 years (dashed lines). The subsurface thermal properties were taken from the $50 \%$ saturated sand and peat values in Table 2, and the recharge rate was $20 \mathrm{~cm} \mathrm{yr}^{-1}$. The results shown in (b) were calculated with Eq. (17) using the same parameters as (a).

due to a sudden and permanent $\left(t_{1}=\infty\right.$, Eq. 10) mean annual surface temperature increase of $2{ }^{\circ} \mathrm{C}$. This is approximately the long-term mean annual surface temperature increase observed by Lewis (1998) in response to deforestation. This is at the lower end of the range $\left(1.6\right.$ to $\left.5.1^{\circ} \mathrm{C}\right)$ in the mean annual surface temperature increases noted by Taniguchi et al. (1998) following forest removal in Western
Australia. The groundwater warming, rather than the temperature, is obtained by setting the initial temperature to zero ( $T_{0}$; Eqs. 10 and 11).

Results are presented for sandy soil and peat soil as these two soils respectively exhibit the highest and lowest thermal diffusivities given in Table 2. Due to the nature of the surface thermal boundary condition, these groundwater warming se- 
ries exhibit a convex upward curvature. The results for the two depths $(5$ and $20 \mathrm{~m})$ indicate that the lag between the surface and subsurface warming increases with increasing depth. For the sandy soil, the temperature at a depth of $20 \mathrm{~m}$ increases by $1.77^{\circ} \mathrm{C}$ after 100 years, whereas at $5 \mathrm{~m}$ depth, this magnitude of warming was realized after only 14 years. Thus, for initially uniform conditions, deeper aquifers will generally remain colder longer than shallow aquifers, as it takes longer for the warming signal to be advected or conducted downwards. Furthermore, Fig. 7a also indicates that soils with a higher thermal diffusivity (i.e., sand) will initially transport the surficial warming signal through the subsurface more rapidly than soils with lower thermal diffusivity (i.e., peat). However, because the subsurface is slowly equilibrating with the new constant surface temperature, the solid series representing the results for the different depths and soils begin to converge as time increases.

In the case of vegetation regrowth, the surface-temperature warming due to the land cover disturbance would be temporary. As an illustrative example, Fig. 7a (dashed lines) shows the groundwater warming produced by Eq. (11) at two depths and for two soils due to a sudden $2{ }^{\circ} \mathrm{C}$ increase in surface temperature that persists for only 25 years $\left(t_{1} ; \mathrm{Eq} .10\right)$. If desired, the equation could be further enhanced to accommodate a gradual cooling phase, rather than the instant cooling employed in the present study, using the more general formula described by Menberg et al. (2014). In Fig. 7a, the dashed and solid lines overlap prior to the cooling phase occurring at 25 years. The dashed temperature curves after 25 years represent the thermal recovery period. The groundwater warming curve for a depth of $5 \mathrm{~m}$ and the more diffusive soil (sand) is sharp, whereas the groundwater warming curve for a depth of $20 \mathrm{~m}$ and the less diffusive soil (peat) is more diffused and lagged. For example, the maximum groundwater warming $\left(0.88^{\circ} \mathrm{C}\right)$ for the peat soil at a depth of $20 \mathrm{~m}$ occurs at 33 years, which is 8 years after the surface warming has ceased. Thus, thermal impacts to coldwater streams caused by deforestation may persist several years after vegetation regrowth has occurred, particularly if groundwater discharge to the stream is sourced from a deeper aquifer. However, these effects would likely not be significant as the warming signal would be strongly damped at such depths.

Figure $7 \mathrm{~b}$ shows the aquifer thermal sensitivities in response to a sudden permanent (solid lines) or temporary (dashed lines) step increase in surface temperature, which correspond to the same warming scenarios as shown in Fig. 7a. As indicated in Eq. (17), these thermal sensitivity curves are similar to the groundwater warming curves (Eq. 11 and Fig. 7a), but are scaled by a factor of $\Delta T^{-1}$. Hence, the thermal sensitivity curves due to a step increase in surface temperature are normalized with respect to the boundary temperature increase and are thus independent of the $\Delta T$ value. The results presented in Fig. 7 clearly demonstrate that shallow groundwater will initially warm rapidly in response to permanent deforestation and then the rate of temperature increase will decrease with time. This arises due to the initially high thermal gradient and heat conduction arising from the abrupt surface step change in temperature. The resultant impacts of groundwater warming on streambed conductive and advective heat fluxes should be considered in models that simulate stream temperature warming due to deforestation - at least for streams where groundwater discharge has been shown to influence stream temperature. Of particular note, small headwater streams, which are often groundwater dominated, can warm more rapidly than larger streams in response to deforestation because, for natural vegetative conditions, smaller streams typically experience more shading than larger rivers (e.g., Caissie, 2006).

The results shown in Fig. 7 are presented for a recharge scenario $\left(q=0.2 \mathrm{~m} \mathrm{yr}^{-1}\right)$. This approach is conservative because recharge environments will typically warm more rapidly in response to rising surface temperatures than discharge environments, as conduction and advection are acting in parallel in the former case. The analytical solutions provided in this study for simulating subsurface warming due to long-term surface-temperature trends (Eqs. 11, 13, and 15) are better suited for recharge environments than discharge environments, as groundwater discharge can bring up warm groundwater from deeper within the aquifer in accordance with the geothermal gradient. This phenomenon is not accounted for in the uniform initial conditions (Eq. 9). These solutions can be modified to allow for linearly increasing temperature with depth to account for the geothermal gradient (Kurylyk and MacQuarrie, 2014; Taniguchi et al., 1999a, b), but this adds complexity to the resultant sensitivity formulae. Also as previously noted, this study is primarily concerned with shallow aquifers where heat fluxes due to surface-temperature changes can dominate the influence of the geothermal gradient.

\subsection{Impacts of climate change on groundwater temperatures}

Equations (13) and (15) can be employed to investigate the sensitivity of groundwater temperatures to long-term gradual surface-temperature changes such as those experienced during climate change. The IPCC (2007) multi-model results (Fig. 2) are globally averaged results, and these data will be used to form the surface boundary conditions for the illustrative examples.

\subsubsection{Exponential and linear boundary conditions}

The IPCC air temperature anomalies for this century produced by the conservative emission scenario B1 were fitted to a linear surface-temperature function (Fig. 2). The best fit between the linear function and the projected B1 air temperature warming was obtained with a slope $\beta$ of $5.41 \times 10^{-10}{ }^{\circ} \mathrm{C} \mathrm{s}^{-1}\left(1.7^{\circ} \mathrm{C}\right.$ per century, see Eq. 12). Also, 

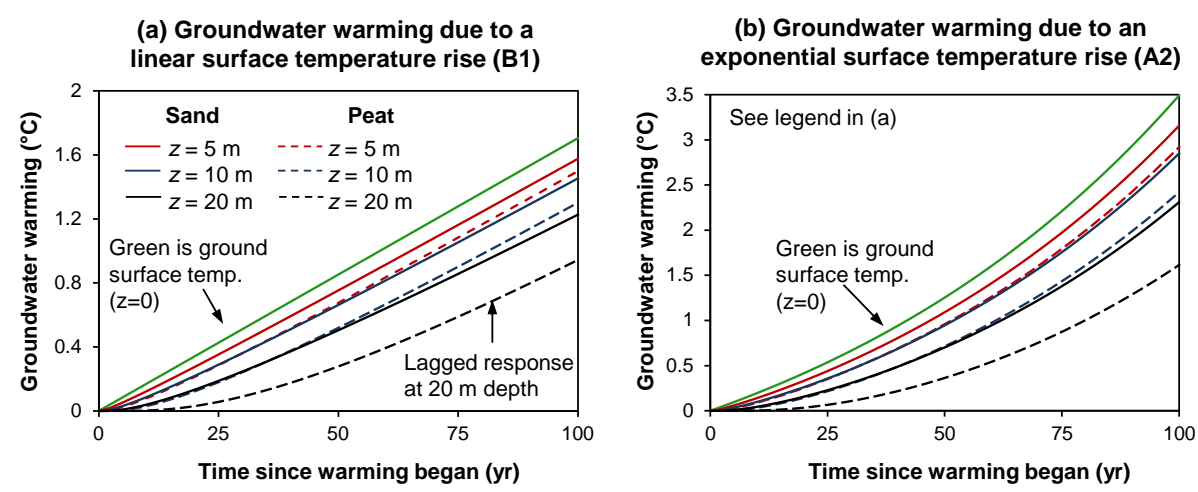

(c) Thermal sensitivity for warming in (a)

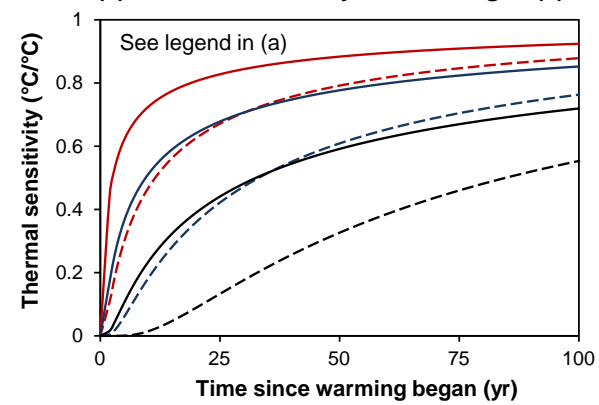

(d) Thermal sensitivity for warming in (b)

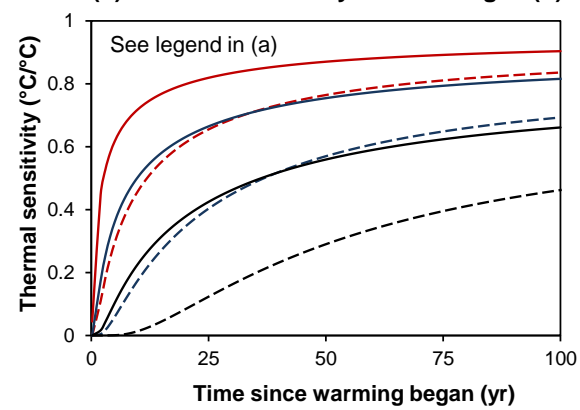

Figure 8. Groundwater temperature warming due to a linear trend (a) and an exponential trend (b) in surface temperature vs. the time since the surface warming began. (c) and (d) groundwater thermal sensitivity vs. time for each of the six scenarios presented in (a) and (b), respectively. The results shown in (a) were obtained with Eq. (13) with $\beta=5.41 \times 10^{-10}{ }^{\circ} \mathrm{C} \mathrm{s}^{-1}$ based on the IPCC B1 projections and setting $T_{0}=0{ }^{\circ} \mathrm{C}$. The results shown in (b) were obtained with Eq. (15) where $T_{1}, b$, and $c$ are $-1.59^{\circ} \mathrm{C}, 1.59^{\circ} \mathrm{C}$, and $3.68 \times 10^{-10} \mathrm{~s}^{-1}$, respectively (to match the IPCC A2 projections). The subsurface thermal properties were for $50 \%$ saturated soil (Table 2), and the recharge rate was $20 \mathrm{~cm} \mathrm{yr}^{-1}$. The aquifer thermal sensitivities shown in (c) and (d) were calculated with Eqs. (18) and (19), respectively.

the exponential function was employed to represent the IPCC multi-model results obtained using the more aggressive, nonlinear A2 emission scenario (Fig. 2). The optimal exponential fit was obtained with fitting parameters $b$ and $c$ of $1.59^{\circ} \mathrm{C}$ and $3.67 \times 10^{-10} \mathrm{~s}^{-1}$, respectively (Eq. 14). The root mean square error (RMSE) values for the exponential and linear fits are presented in Fig. 2. The fitting parameter $T_{1}\left(T_{0}-b\right)$ can be adjusted to obtain the desired initial temperature, and herein we consider the subsurface warming (rather than the temperature per se) by setting initial temperatures to $0{ }^{\circ} \mathrm{C}$ (i.e., $T_{1}=-b$ ).

\subsubsection{Groundwater warming due to climate change}

Equation (13) was employed to illustrate how an idealized, shallow aquifer would respond to a slow linear surface temperature rise (Fig. 3c). Figure 8a shows the groundwater warming results at different depths and for different soils calculated with Eq. (13) by applying a $0.017^{\circ} \mathrm{C} \mathrm{yr}^{-1}$ linear surface warming as the boundary condition (B1; Fig. 2). The starting date is the year 2000. Similar to the results presented above for land cover disturbances, the surface warming is more rapidly propagated to shallower depths (i.e., $5 \mathrm{~m}$ vs. $20 \mathrm{~m}$ ) and for more thermally diffusive soils (sand vs. peat). After 100 years, the $1.7^{\circ} \mathrm{C}$ surface warming produced a $1.6^{\circ} \mathrm{C}$ increase in groundwater temperature for the sandy soil at a depth of $5 \mathrm{~m}$ (solid red series), but only a $0.94{ }^{\circ} \mathrm{C}$ increase for the peat soil at a depth of $20 \mathrm{~m}$ (dashed-black series; Fig. 8a).

Figure $8 \mathrm{~b}$ shows the groundwater warming results produced with the analytical solution with an exponentially increasing surface temperature (Eq. 15). The soil thermal properties and recharge rates are identical for the results shown in Fig. $8 \mathrm{a}$ and $\mathrm{b}$, and thus the only difference between the two figure panels is the surface-temperature boundary condition. The results shown in Fig. 8a and b for a given soil type and depth (i.e., same color and line type) begin to significantly diverge after approximately 30 years because the IPCC A2 multi-model projections exhibit more extreme warming than the $\mathrm{B} 1$ projections after 2030 (Fig. 2).

\subsubsection{Groundwater thermal sensitivity due to climate change}

Figure $8 \mathrm{c}$ and $\mathrm{d}$ show the groundwater thermal sensitivity (Eqs. 18 and 19) results due to the linear surface warming and the exponential surface warming shown in Fig. 8a and b, respectively. Although the surface warming scenario shown in 
Fig. 8b is much more pronounced than that shown in Fig. 8a, it is interesting to note that the groundwater thermal sensitivity results for these warming scenarios are very similar (Fig. 8c and d), since the thermal sensitivity is essentially the thermal effect divided by the driving cause.

Due to the lag between the surface warming and the subsurface thermal response, the subsurface thermal regime will never reach equilibrium with the surface thermal regime when the boundary condition represents continuous surface temperature increases. Hence, the groundwater thermal sensitivities will never attain unity unless a stable surface-temperature regime is eventually established. However, Fig. 8c and d indicate that the groundwater thermal sensitivity increases with time as the magnitudes of both the surface and subsurface temperature warming increase, and thus the relative impact of the lag decreases. For example, after 100 years, the thermal sensitivity of the sandy soil at a depth of $5 \mathrm{~m}$ is about 0.90 for both the B1 linear warming scenario (Fig. 8c) and the A2 exponential warming scenario (Fig. 8d). Thus, shallow groundwater at this depth and for these conditions would be expected to warm by approximately $90 \%$ of the surface temperature increase within 100 years.

\subsection{Implications for groundwater-dominated streams and rivers}

The consideration of groundwater temperature in stream temperature modeling is especially relevant in small streams where surface heat fluxes do not dominate the total energy budget. In fact, small streams are generally very dependent on groundwater inputs and temperatures, and their low thermal capacity (shallow depth and volume) makes them very vulnerable to any surface or subsurface-energy flux modifications (e.g., Matheswaran et al., 2014). This has been shown in many timber harvesting studies, where the smallest streams have experienced the greatest increase in stream temperature following forest removal (e.g., Brown and Krygier, 1970). Thus, quantifying future changes in shallow groundwater flow and temperatures is essential for a better understanding of the future thermal regimes of groundwater-dominated rivers and associated impacts to aquatic organisms (Kanno et al., 2014).

The results presented in Fig. 8 demonstrate the limitations inherent in inferring future stream warming from stream thermal sensitivities obtained from seasonal stream and air temperature data. For instance, the seasonal groundwater thermal sensitivity $(\Omega)$ values presented in Fig. 6 indicate that groundwater temperature beyond $10 \mathrm{~m}$ depth generally exhibits minimal sensitivity to seasonal variations in weather. Thus, stream thermal sensitivities obtained from seasonal air and stream temperature data are typically low for groundwater-dominated streams (Kelleher et al., 2012). However, as Fig. 8c and d illustrate, groundwater warming at depths greater than $10 \mathrm{~m}$ may still be significant in response to long-term surface-temperature changes, such as would be experienced under climate change. Due to the inter-relationships between the thermal regimes of stream and aquifers and the differences between the thermal sensitivities of shallow aquifers to short-term (Fig. 6) and longterm (e.g., Figs. 7b and 8) surface-temperature changes, it is not generally valid to extrapolate thermal sensitivities for groundwater-dominated streams obtained from sub-annual data to project long-term stream warming.

These results also demonstrate the potential limitations of using relatively short (e.g., $<25$ years) records of interannual air and water temperature data to obtain estimations of future stream warming (e.g., Luce et al., 2014). Results for the present study (Fig. 8c and d) indicate that even at a timescale of 25 years, the thermal sensitivities of relatively shallow (e.g., $10 \mathrm{~m}$ ) groundwater reservoirs may be low compared to thermal sensitivities that could be attained after 100 years of surface warming. These results suggest that what is interpreted as a damped stream thermal sensitivity to inter-annual air temperature variability in the case of groundwater-dominated streams may actually be a delayed thermal sensitivity due to the lag in the warming of groundwater and associated streambed heat fluxes. We acknowledge, however, that employing thermal sensitivities derived from inter-annual temperature data to project future stream warming is preferable to considering thermal sensitivities from seasonal temperature data (Luce et al., 2014). The appropriateness of these methods depends on the depth to the aquifer, the degree of groundwater contribution to the stream/river, the subsurface thermal properties, and the timescale of interest.

\subsection{Addressing groundwater warming in stream temperature models}

The present study demonstrates the importance of surfacetemperature forcing on groundwater temperature, particularly for shallow aquifers. The potential influence of shallow groundwater warming on stream temperatures is not generally considered in existing empirical stream temperature models. The equations proposed in this study can be used to develop an approach to approximate the timing and magnitude of groundwater temperature warming in response to long-term surface-temperature changes. As described below, this information may be integrated within existing stream temperature models that consider streambed heat fluxes.

The upper boundary condition for the equations presented in this study is the ground surface temperature. Thus, the projected trends in catchment land surface temperature due to future climate change or land cover disturbances must be obtained prior to utilizing these equations. In the case of climate change without related snowpack changes, mean annual surface-temperature trends are often assumed to follow mean annual air temperature trends (see Mann and Schmidt, 2003). This simplification facilitates the boundary condition generation because air temperature trends can be readily ob- 
Table 3. Parameters for equations considered in this study.

\begin{tabular}{|c|c|c|c|c|}
\hline Symbol & $\begin{array}{l}\text { Physical } \\
\text { meaning }\end{array}$ & Units & $\begin{array}{l}\text { Determination } \\
\text { method }\end{array}$ & $\begin{array}{l}\text { Example } \\
\text { sources }\end{array}$ \\
\hline$D$ & $\begin{array}{l}\text { Thermal } \\
\text { diffusivity }\end{array}$ & $\mathrm{m}^{2} \mathrm{~s}^{-1}$ & $\begin{array}{l}\text { Obtain from tabulated values } \\
\text { (e.g., Table 2) }\end{array}$ & $\begin{array}{l}\text { (Oke, 1978; Monteith and } \\
\text { Unsworth, 2007) }\end{array}$ \\
\hline$z, z_{\text {eff }}$ & $\begin{array}{l}\text { Depth, } \\
\text { effective depth }\end{array}$ & $\mathrm{m}$ & $\begin{array}{l}\text { Geophysics, groundwater table } \\
\text { maps, local wells }\end{array}$ & $\begin{array}{l}\text { (Fan et al., 2013; } \\
\text { Snyder, 2008) }\end{array}$ \\
\hline$U, q$ & $\begin{array}{l}\text { Thermal plume } \\
\text { velocity, } \\
\text { groundwater } \\
\text { recharge }^{2}\end{array}$ & $\mathrm{~ms}^{-1}$ & $\begin{array}{l}\text { Thermal tracing, lysimeters, } \\
\text { local recharge maps }\end{array}$ & $\begin{array}{l}\text { (Healy, 2010; Scanlon et al., } \\
\text { 2002) }\end{array}$ \\
\hline$T_{0}$ & Initial temperature & ${ }^{\circ} \mathrm{C}$ & $\begin{array}{l}\text { Mean annual surface } \\
\text { temperature }^{3}\end{array}$ & (USEPA, 2013) \\
\hline $\begin{array}{l}T_{\mathrm{m}}, A, \Delta T \\
T_{1}, \beta, b \\
\text { and } c\end{array}$ & $\begin{array}{l}\text { Surface- } \\
\text { temperature } \\
\text { fitting parameters }\end{array}$ & Various & $\begin{array}{l}\text { Climate model output, surface- } \\
\text { energy balance models } 4\end{array}$ & $\begin{array}{l}\text { (Kurylyk et al., 2013; } \\
\text { Mellander et al., 2007; } \\
\text { Taniguchi, 1993) }\end{array}$ \\
\hline
\end{tabular}

tained from the output of climate models. However, in the case of land cover changes (e.g., urbanization) or snowpack evolution, mean annual air temperature trends may be decoupled from mean annual surface-temperature trends (Mann and Schmidt, 2003; Mellander et al., 2007). In this situation, a simple surface heat-flux balance model can be applied to calculate the surface-temperature changes due to changes in the climate and/or land cover. A detailed discussion on appropriate techniques for simulating these relationships can be found in Mellander et al. (2007), Kurylyk et al. (2013), and Jungqvist et al. (2014).

Once the surface-temperature trends are obtained, they can then be fitted to the appropriate boundary condition function (Fig. 3). The associated analytical solution (Table 1) and groundwater thermal sensitivity formula can be utilized to perform simulations of future subsurface warming and/or groundwater thermal sensitivity due to the surfacetemperature change. It should be noted that these solutions only calculate increases in mean annual groundwater temperature and do not account for seasonality. It is generally reasonable to assume that the amplitude and timing of the seasonal groundwater cycle will not be greatly influenced by climate change (Taylor and Stefan, 2009), provided snowpack conditions or the seasonality of soil moisture will not change significantly (Kurylyk et al., 2013).

In addition to the surface-temperature boundary condition terms, the analytical solutions must be parameterized with subsurface thermal properties, vertical groundwater flow information, and effective aquifer depth. Subsurface thermal properties can be obtained from information regarding the soil type and typical water saturation of the sediment overlying the aquifer (Table 2). Vertical groundwater flow rates can be obtained from field measurements (e.g., using heat as a hydrologic tracer, Gordon et al., 2012; Lautz, 2010; Rau et al., 2014) or from regional or local groundwater recharge and discharge maps. Potential changes in groundwater recharge (Crosbie et al., 2011; Kurylyk and MacQuarrie, 2013; Hayashi and Farrow, 2014) and groundwater discharge (Kurylyk et al., 2014a; Levison et al., 2014) due to changes in climate or land cover could also be considered. The aquifer effective depth can be crudely estimated as the average unsaturated zone or aquitard thickness overlying the aquifer (e.g., Fig. 4). Such information may be available from well data, geophysical surveys, or regional maps of the groundwater table depth (Fan et al., 2013; Snyder, 2008). Further research is required to assess approaches for more accurately determining the effective aquifer depth. A reasonable range of the input variables to these equations should be considered to generate an envelope of predicted groundwater warming (see Fig. 4 of Menberg et al., 2014). Such a range could incorporate uncertainties arising from, for example, heterogeneities in soil thermal properties and interannual variability in groundwater recharge (Hayashi and Farrow, 2014). Table 3 lists alternative options for parameterizing the equations presented in this study. The parameter values used in the present study are representative of conditions often observed.

To determine the influence of warming groundwater on stream temperatures, the future groundwater thermal sensitivity can be applied to estimate the resultant changes to 
streambed heat fluxes. There are different approaches available for estimating streambed heat fluxes from subsurface temperatures depending on whether the total streambed energy flux or the apparent sensible flux is being considered (e.g., Caissie et al., 2014; Moore et al., 2005), but in either case, the streambed fluxes depend on subsurface temperature, particularly the temperature immediately below the stream. These changes in streambed heat fluxes can then be combined with simulated changes in stream surface heat fluxes, and the resultant change in stream temperature can be obtained in a deterministic stream temperature model. Such an approach to estimate long-term evolution of stream temperatures would be more realistic than considering a stream temperature model driven by air temperature only, as both surface and streambed heat fluxes can be important in stream temperature dynamics.

\section{Limitations}

The unsteady heat advection-diffusion equation utilized in this study (Eq. 2) assumes one-dimensional groundwater flow and heat transport, spatiotemporally invariant groundwater flow, isothermal conditions between the soil grains and water at every point, and homogeneous thermal properties. Flashy groundwater flow regimes with very short residence times (e.g., aquifers with large fractures) may invalidate the assumption of thermal equilibrium between the subsurface environment and the mobile water. In such settings, recharge seasonality may exert strong control on the temperature of groundwater discharge (Luhmann et al., 2011). Horizontal groundwater flow can perturb subsurface thermal regimes, at least in regions with significant horizontal thermal gradients (Ferguson and Bense, 2011; Reiter, 2001), and there may be a vertical discontinuity in vertical water flow across aquifers due to horizontal discharge to surface water bodies. Aquifers that exhibit considerable lateral hydraulic heterogeneities may be characterized by flow regimes that are not well represented by the conceptual model (Fig. 4).

Herein, we propose that the average depth to the groundwater table may be a reasonable approximation for the effective depth $\left(z_{\text {eff }}\right)$. This approach assumes that the groundwater temperature at the bottom of the vertical flow tubes is fully mixed and that there is no modification of the temperature signal as the groundwater flows horizontally towards the discharge location (Fig. 4). This assumption may be violated in very shallow aquifers with slow groundwater flow (i.e., low horizontal advection and dispersion) due to vertical conductive heat fluxes from the surface in the vicinity of the discharge location.

In shallow aquifers, groundwater velocity varies seasonally and is driven by the seasonality of precipitation, but subsurface hydraulic storage properties tend to damp the seasonality of groundwater flow in comparison to precipitation. Equation (2) also assumes that no soil thawing occurs as a result of the surface-temperature change, but latent heat absorbed during soil thaw can significantly retard subsurface warming (Kurylyk et al., 2014b). Ignoring soil thaw is reasonable, except in permafrost regions, because in ephemerally freezing regions the dynamic freeze-thaw process only influences the seasonality of groundwater temperature, and does not significantly influence the change in mean annual groundwater temperature in response to long-term climate change (Kurylyk et al., 2014a).

At very shallow depths (e.g., $<3 \mathrm{~m}$ ), the subsurface thermal regime can be considered to be in equilibrium with the mean annual surface temperature. Because the lag between surface and subsurface warming is negligible in this case, the solutions presented in this study are not overly useful at very shallow depths. Also, at greater depths (e.g., $25 \mathrm{~m}$ ), the influence of the geothermal gradient should be explicitly considered. In such cases, the equations proposed in this study can be modified to incorporate a geothermal gradient (Kurylyk and MacQuarrie, 2014; Taniguchi et al., 1999a, b). Despite these limitations, the analytical solutions presented here can be employed to obtain reasonable estimates of the evolution of mean annual groundwater temperature due to climate change and land cover disturbances for a broad range of aquifer depths. For example, Menberg et al. (2014) applied a modified form of Eq. (11) to calculate groundwater warming trends that generally concurred with measured (1970-2010) groundwater warming trends recorded at forested and agricultural sites in Germany. We anticipate that other studies may also benefit from these approaches.

\section{Summary and conclusions}

Stream temperature models often ignore the potential for future groundwater warming. This simplifying assumption is employed because mean annual groundwater temperature is relatively constant (or thermally insensitive) on the intraannual or short inter-annual timescales that it is typically measured. We have suggested in this study that although seasonal surface-temperature changes are damped in the shallow subsurface, long-term changes in surface temperatures can be propagated to much greater depths. This phenomenon has been known for some time in the field of thermal geophysics (e.g., Lesperance et al., 2010), but it is generally overlooked in stream temperature modeling. Due to the difference in the subsurface thermal response to seasonal and multi-decadal surface-temperature changes, it may be inappropriate to infer multi-decadal warming of groundwater-dominated streams based on linear regressions of short-term air and water temperature data.

Previous studies have identified the potential importance of considering shallow groundwater temperature warming when projecting future stream temperature (Kurylyk et al., 2013, 2014a). These studies have employed methods that either require extensive surface and subsurface-temperature 
data collection or detailed numerical modeling. In many cases, these methods may be prohibitive. Several analytical solutions and associated groundwater thermal sensitivity equations are presented in this study as alternative approaches for estimating a range for the potential timing and magnitude of future groundwater warming in response to climate change or land cover disturbances. These are most applicable to idealized environments, but the methods can be employed to obtain first-order approximations of future groundwater warming in natural environments (see Menberg et al., 2014). The subsurface warming scenarios can be considered within existing stream temperature models to investigate whether groundwater warming is an important consideration for the future thermal regime of a particular stream (Snyder et al., 2015).

The present study has highlighted the importance of shallow groundwater sensitivity to surface warming. Although groundwater warming has been inferred from subsurface temperature-depth profiles at many sites, few long-term data sets of directly measured groundwater temperature exist to corroborate the methods proposed herein (Menberg et al., 2014). The initiation of long-term shallow groundwater temperature monitoring sites would provide a better understanding of the processes linking atmospheric and subsurface warming (e.g., Caldwell et al., 2014).

\section{The Supplement related to this article is available online at doi:10.5194/hess-19-2469-2015-supplement.}

Acknowledgements. We thank Craig Snyder and Nathaniel Hitt of the US Geological Survey for providing helpful comments on an earlier version of this paper. B. Kurylyk was funded through a Natural Sciences and Engineering Research Council of Canada postgraduate scholarship (CGSD3), an O'Brien Fellowship, and a Canadian Water Resources Association Dillon Scholarship. Charles Luce, an anonymous reviewer and the associate editor, Ross Woods, provided constructive insight that improved the quality of this contribution.

Edited by: R. Woods

\section{References}

Alexander, M. D.: The thermal regime of shallow groundwater in a clearcut and forested streamside buffer, PhD Dissertation, University of New Brunswick, Fredericton, NB, Canada, 436 pp., 2006.

Allan, J. D. and Castillo, M. M.: Stream ecology: structure and function of running waters, 2nd Edn., Springer, Dordrecht, the Netherlands, 2007.

Anderson, M.: Heat as a ground water tracer, Ground Water, 43, 951-968, 2005.

Arismendi, M., Safeeq, M., Dunham, J. B., and Johnson, S. L.: Can air temperature be used to project influences of climate change on stream temperature?, Environ. Res. Lett., 9, 084015, doi:10.1088/1748-9326/9/8/084015, 2014.

Bal, G., Rivot, E., Bagliniére, J.-L., White, J., and Prévost, E.: A hierarchical Bayesian model to quantify uncertainty of stream water temperature forecasts, PLoS ONE, 9, e115659, doi:10.1371/journal.pone.0115659, 2014.

Bonan, G.: Ecological climatology, Cambridge University Press, Cambridge, UK, 2008.

Brown, G. W. and Krygier, J. T.: Effects of clear-cutting on stream temperature, Water Resour. Res., 6, 1133-1139, doi:10.1029/WR006i004p01133, 1970.

Brown, L. E. and Hannah, D. M.: Spatial heterogeneity of water temperature across an alpine river basin, Hydrol. Process., 7 , 954-967, doi:10.1002/hyp.6982, 2008.

Burn, C. R.: The response (1958-1997) of permafrost and nearsurface ground temperatures to forest fire, Takhini River valley, southern Yukon Territory, Can. J. Earth Sci., 35, 184-199, doi:10.1139/e97-105, 1998.

Caissie, D.: The thermal regime of rivers: a review, Freshwat. Biol., 51, 1389-1406, doi:10.1111/j.1365-2427.2006.01597.x, 2006.

Caissie, D., Kurylyk, B. L., St-Hilaire, A., El-Jabi, N., and MacQuarrie, K. T. B.: Stream temperature dynamics and streambed heat fluxes in streams experiencing seasonal ice cover, J. Hydrol., 519, 1441-1452, doi:10.1016/j.jhydrol.2014.09.034, 2014.

Caldwell, R. R., Eddy-Miller, C., Barlow, J. R. B., Wheeler, J., and Constantz, J.: Increased understanding of watershed dynamics through the addition of stream and groundwater temperature monitoring at USGS groundwater streamgages, Paper No. 1943, Geological Society of America Meeting, Vancouver, British Columbia, 2014.

Caldwell, P., Segura, C., Laird, S. G., Ge, S., McNulty, S. G., Sandercock, M., Boggs, J., and Vose, J. M.: Short-term stream water temperature observations permit rapid assessment of potential climate change impacts, Hydrol. Process., 29, 2196-2211, doi:10.1002/hyp.10358, 2015.

Carslaw, H. S. and Jaeger, J. C.: Conduction of heat in solids, Clarendon Press, Oxford, 1959

Chen, C. H., Wang, C. H., Chen, D. L., Sun, Y. K., Lui, J. Y., Yeh, T. K., Yen, H. Y., and Chang, S. H.: Comparisons between air and subsurface temperatures in Taiwan for the past century: a global warming perspective, in: Groundwater and Subsurface Environments: Human Impacts in Asian Coastal Cities, Ch. 10, edited by: Taniguchi, M., Springer, Tokyo, Japan, 187200, doi:10.1007/978-4-431-53904-9_10, 2011.

Constantz, J.: Interaction between stream temperature, streamflow, and groundwater exchanges in Alpine streams, Water Resour. Res., 34, 1609-1615, doi:10.1029/98WR00998, 1998.

Crosbie, R. S., Dawes, W. R., Charles, S. P., Mpelasoka, F. S., Aryal, S., Barron, O., and Summerell, G. K.: Differences in future recharge estimates due to GCMs, downscaling methods and hydrological models, Geophys. Res. Lett., 38, L11406, doi:10.1029/2011GL047657, 2011.

Cunjak, R. A., Linnansaari, T., and Caissie, D.: The complex interaction of ecology and hydrology in a small catchment: a salmon's perspective, Hydrol. Process., 27, 741-749, doi:10.1002/hyp.9640, 2013.

Döll, P. and Fiedler, K.: Global-scale modeling of groundwater recharge, Hydrol. Earth Syst. Sci., 12, 863-885, doi:10.5194/hess-12-863-2008, 2008. 
Domenico, P. A. and Schwartz, F. W.: Physical and chemical hydrogeology, Wiley, New York, 1990.

Ebersole, J. L., Liss, W. J., and Frissell, C. A.: Cold water patches in warm streams: physicochemical characteristics and the influence of shading, J. Am. Water Resour. Assoc., 39, 355-368, doi:10.1111/j.1752-1688.2003.tb04390.x, 2003.

Elliott, J. M. and Elliott, J. A.: Temperature requirements of Atlantic salmon Salmo salar, brown trout Salmo trutta and Arctic charr Salvelinus alpinus: predicting the effects of climate change, J. Fish Biol., 77, 1793-1817, doi:10.1111/j.10958649.2010.02762.x, 2010.

Fan, Y., Li, H., and Miguez-Macho, G.: Global patterns of groundwater table depth, Science, 339, 940-943, doi:10.1126/science.1229881, 2013.

Farouki, O. T.: The thermal properties of soils in cold regions, Cold Reg. Sci. Technol., 5, 67-75, 1981.

Ferguson, G. and Bense, V.: Uncertainty in 1D heat-flow analysis to estimate groundwater discharge to a stream, Ground Water, 49, 336-347, doi:10.1111/j.1745-6584.2010.00735.x, 2011.

Ferguson, G. and Woodbury, A. D.: The effects of climatic variability on estimates of recharge from temperature profiles, Ground Water, 43, 837-842, doi:10.1111/j.1745-6584.2005.00088.x, 2005.

Figura, S., Livingstone, D. M., Hoehn, E., and Kipfer, R.: Regime shift in groundwater temperature triggered by Arctic oscillation, Geophys. Res. Lett., 38, L23401, doi:10.1029/2011GL049749, 2011.

Figura, S., Livingstone, D. M., and Kipfer, R.: Forecasting groundwater temperature with linear regression models using historical data, Groundwater, doi:10.1111/gwat.12289, in press, 2014.

Garner, G., Hannah, D. M., Sadler, J. P., and Orr, H. G.: River temperature regimes of England and Wales: spatial patterns, interannual variability and climate sensitivity, Hydrol. Process., 28, 5583-5598, doi:10.1002/hyp.9992, 2014.

Gelhar, L. W. and Wilson, J. L.: Ground-water quality modeling, Ground Water, 12, 399-408, doi:10.1111/j.17456584.1974.tb03050.x, 1974.

Gordon, R. P., Lautz, L. K., Briggs, M. A., and McKenzie J. M.: Automated calculation of vertical pore-water flux from field temperature time series using the VFLUX method and computer program, J. Hydol., 420-421, 142-158, doi:10.1016/j.jhydrol.2011.11.053, 2012.

Gu, C., Anderson, W. P., Colby, J. D., and Coffey, C. L.: Air-stream temperature correlation in forested and urban headwater streams in the Southern Appalachians, Hydrol. Process., 29, 1110-1118, doi:10.1002/hyp.10225, 2015.

Guenther, S. M., Gomi, T., and Moore, R. D.: Stream and bed temperature variability in a coastal headwater catchment: influences of surface-subsurface interactions and partialretention forest harvesting, Hydrol. Process., 28, 1238-1249, doi:10.1002/hyp.9673, 2014.

Gunawardhana, L. N. and Kazama, S.: Climate change impacts on groundwater temperature change in the Sendai plain, Japan, Hydrol. Process., 25, 2665-2678, doi:10.1002/hyp.8008, 2011.

Gunawardhana, L. N. and Kazama, S.: Statistical and numerical analyses of the influence of climate variability on aquifer water levels and groundwater temperatures: The impacts of climate change on aquifer thermal regimes, Global Planet. Change, 8687, 66-78, doi:10.1016/j.gloplacha.2012.02.006, 2012.
Hannah, D. M. and Garner, G.: River water temperature in the United Kingdom: Changes over the $20^{\text {th }}$ century and possible changes over the $21^{\text {st }}$ century, Prog. Phys. Geogr., 39, 68-92, doi:10.1177/0309133314550669, 2015.

Hannah, D. M., Malcolm, I. A., Soulsby, C., and Youngson, A. F.: Heat exchanges and temperatures within a salmon spawning stream in the Cairngorms, Scotland: seasonal and sub-seasonal dynamics, River Res. Appl., 20, 635-652, doi:10.1002/rra.771, 2004.

Hatch, C. E., Fisher, A. T., Revenaugh, J. S., Constantz, J., and Ruehl, C.: Quantifying surface water-groundwater interactions using time series analysis of streambed thermal records: Method development, Water Resour. Res., 42, W10410, doi:10.1029/2005WR004787, 2006.

Hayashi, M. and Farrow, C. W.: Watershed-scale response of groundwater recharge to inter-annual and inter-decadal variability in precipitation (Alberta, Canada), Hydrogeol. J., 22, 18251839, doi:10.1007/s10040-014-1176-3, 2014.

Healy, R. W.: Estimating groundwater recharge, Cambridge University Press, Cambridge, UK, 2010.

Henriksen, A. and Kirkhusmo, L. A.: Effects of clear-cutting of forest on the chemistry of a shallow groundwater aquifer in southern Norway, Hydrol. Earth. Syst. Sci., 4, 323-331, doi:10.5194/hess4-323-2000, 2000.

Hilderbrand, R. H., Kashiwagi, M. T., and Prochaska, A. P.: Regional and local scale modeling of stream temperatures and spatio-temporal variation in thermal sensitivities, Environ. Manage., 54, 14-22, doi:10.1007/s00267-014-0272-4, 2014.

Hitt, N. P.: Immediate effects of wildfire on stream temperature, J. Freshwater Ecol., 18, 171-173, doi:10.1080/02705060.2003.9663964, 2003.

Hoehn, E. and Cirpka, O. A.: Assessing residence times of hyporheic ground water in two alluvial flood plains of the Southern Alps using water temperature and tracers, Hydrol. Earth Syst. Sci., 10, 553-563, doi:10.5194/hess-10-553-2006, 2006.

IPCC - Intergovernmental Panel on Climate Change: AR4 MultiModel Average of Detrended Globally Averaged TAS Anomalies, available at: http://www.ipcc-data.org/data/ar4multimodel_ globalmeantas.txt (last access: 1 September 2014), 2007.

Isaak, D. J., Luce, C. H., Rieman, B. E., Nagel, D. E., Peterson, E. E., Horan, D. L., Parkes, S., and Chandler, G. L.: Effects of climate change and wildfire on stream temperatures and salmonid thermal habitat in a mountain river network, Ecol. Appl., 20, 1350-1371, doi:10.1890/09-0822.1, 2010.

Isaak, D. J., Wollrab, S., Horan, D., and Chandler, G.: Climate change effects on stream and river temperatures across the northwest US from 1980-2009 and implications for salmonid fishes, Climatic Change, 113, 499-524, doi:10.1007/s10584-011-0326z, 2012.

Janisch, J. E., Wondzell, S. M., and Ehinger, W. J.: Headwater stream temperature: Interpreting response after logging, with and without riparian buffers, Washington, USA, Forest Ecol. Manage., 270, 302-313, doi:10.1016/j.foreco.2011.12.035, 2012.

Johnson, M. F., Wilby, R. L., and Toone, J. A.: Inferring air-water temperature relationships from river and catchment properties, Hydrol. Process., 28, 2912-2928, doi:10.1002/hyp.9842, 2014.

Johnson, S. L.: Stream temperature: scaling of observations and issues for modeling, Hydrol. Process., 17, 497-499, doi:10.1002/hyp.5091, 2003. 
Jungqvist, G., Oni, S. K., Teutschbein, C., and Futter, M. N.: Effect of climate change on soil temperature in Swedish boreal forests, PloS One, 9, e93957, doi:10.1371/journal.pone.0093957, 2014.

Kanno, Y., Vokoun, J. C., and Letcher, B. H.: Paired stream-air temperature measurements reveal fine-scale thermal heterogeneity within headwater brook trout stream networks, River Res. Appl., 30, 745-755, doi:10.1002/rra.2677, 2014.

Kelleher, C., Wagener, T., Gooseff, M., McGlynn, B., McGuire, K., and Marshall, L.: Investigating controls on the thermal sensitivity of Pennsylvania streams, Hydrol. Process., 26, 771-785, doi:10.1002/hyp.8186, 2012.

Kurylyk, B. L. and MacQuarrie, K. T. B.: The uncertainty associated with estimating future groundwater recharge: A summary of recent research and an example from a small unconfined aquifer in a northern humid-continental climate, J. Hydrol., 492, 244253, doi:10.1016/j.jhydrol.2013.03.043, 2013.

Kurylyk, B. L. and MacQuarrie, K. T. B.: A new analytical solution for assessing climate change impacts on subsurface temperature, Hydrol. Process., 28, 3161-3172, doi:10.1002/hyp.9861, 2014.

Kurylyk, B. L., Bourque, C. P. A., and MacQuarrie, K. T. B.: Potential surface temperature and shallow groundwater temperature response to climate change: an example from a small forested catchment in east-central New Brunswick (Canada), Hydrol. Earth Syst. Sci., 17, 2701-2716, doi:10.5194/hess-17-27012013, 2013.

Kurylyk, B. L., MacQuarrie, K. T. B., and Voss, C. I.: Climate change impacts on the temperature and magnitude of groundwater discharge from shallow, unconfined aquifers, Water Resour. Res., 50, 3253-3274, doi:10.1002/2013WR014588, 2014a.

Kurylyk, B. L., MacQuarrie, K. T. B., and McKenzie, J. M.: Climate change impacts on groundwater and soil temperature in cold and temperate regions: Implications, mathematical theory, and emerging simulation tools, Earth-Sci. Rev., 138, 313-334, doi:10.1016/j.earscirev.2014.06.006, 2014b.

Kurylyk, B. L., MacQuarrie K. T. B., Linnansaari, T., Cunjak, R. A., and Curry, R. A.: Preserving, augmenting, and creating coldwater thermal refugia in rivers: concepts derived from research on the Miramichi River, New Brunswick (Canada), Ecohydrology, doi:10.1002/eco.1566, in press, 2015.

Lapham, W. W.: Use of temperature profiles beneath streams to determine rates of ground-water flow and vertical hydraulic conductivity, US Geological Survey Water Supply Paper 2337, US Geological Survey, Denver, CO, 44 pp., 1989.

Lautz, L. K.: Impacts of nonideal field conditions on vertical water velocity estimates from streambed temperature time series, Water Resour. Res., 46, W01509, doi:10.1029/2009WR007917, 2010.

Leach, J. A. and Moore, R. D.: Stream temperature dynamics in two hydrogeomorphically distinct reaches, Hydrol. Process., 25, 679-690, doi:10.1002/hyp.7854, 2011.

Lesperance, M., Smerdon, J. E., and Beltrami, H.: Propagation of linear surface air temperature trends into the terrestrial subsurface, J. Geophys. Res.-Atmos., 115, D21115, doi:10.1029/2010JD014377, 2010.

Levison, J., Larocque, M., and Ouellet, M. A.: Modeling low-flow bedrock springs providing ecological habitats with climate change scenarios, J. Hydrol., 515, 16-28, doi:10.1016/j.jhydrol.2014.04.042, 2014.
Lewis, T. J.: The effect of deforestation on ground surface temperatures, Global Planet. Change, 18, 1-13, doi:10.1016/S09218181(97)00011-8, 1998.

Lewis, T. J. and Wang, K. L.: Geothermal evidence for deforestation induced warming: Implications for the climatic impact of land development, Geophys. Res. Lett., 25, 535-538, doi:10.1029/98GL00181, 1998.

Liljedahl, A., Hinzman, L., Busey, R, and Yoshikawa, K.: Physical short-term changes after a tussock tundra fire, Seward Peninsula, Alaska, J. Geophys. Res.-Earth, 112, F02S07, doi:10.1029/2006JF000554, 2007.

Luce, C. H., Tonina, D., Gariglio, F., and Applebee, R.: Solutions for the diurnally forced advection-diffusion equation to estimate bulk fluid velocity and diffusivity in streambeds from temperature time series, Water Resour. Res., 49, 1-19, doi:10.1029/2012WR012380, 2013.

Luce, C. H., Staab, B., Kramer, M., Wenger, S., Isaak, D., and McConnell, C.: Sensitivity of summer stream temperatures to climate variability in the Pacific Northwest, Water Resour. Res., 50, 3428-3443, doi:10.1002/2013WR014329, 2014.

Luhmann, A. J., Covington, M. D., Peters, A. J., Alexander, S. C., Anger, C. T., Green, J. A., Runkel, A. C., Alexander Jr., E. C.: Classification of thermal patterns at karst springs and cave streams, Ground Water, 49, 324-335, doi:10.1111/j.17456584.2010.00737.x, 2011.

MacDonald, R. J., Boon, S., Byrne, J. M., Robinson, M. D., and Rasmussen, J. B.: Potential future climate effects on mountain hydrology, stream temperature, and native salmonid life history, Can. J. Fish. Aquat. Sci., 71, 189-202, doi:10.1139/cjfas-20130221, 2014.

Mann, M. E. and Schmidt, G. A.: Ground vs. surface air temperature trends. Implications for borehole surface temperature reconstructions, Geophys. Res. Lett., 30, 1607, doi:10.1029/2003GL017170, 2003.

Markle, J. M. and Schincariol, R. A.: Thermal plume transport from sand and gravel pits - Potential thermal impacts on cool water streams, J. Hydrol., 338, 174-195, doi:10.1016/j.jhydrol.2007.02.031, 2007.

Matheswaran, K., Blemmer, M., Thorn, P., Rosbjerg, D., and Boegh, E.: Investigation of stream temperature response to nonuniform groundwater discharge in a Danish lowland stream, River Res. Appl., doi:10.1002/rra.2792, in press, 2014.

Mayer, T. D.: Controls of summer stream temperature in the Pacific Northwest, J. Hydrol., 475, 323-335, doi:10.1016/j.jhydrol.2012.10.012, 2012.

Meisner, J. D., Rosenfeld, J. S., and Regier, H. A.: The role of groundwater in the impact of climate warming on stream salmonines, Fisheries, 13, 2-8, 1988.

Mellander, P., Lofvenius, M. O., and Laudon, H.: Climate change impact on snow and soil temperature in boreal Scots pine stands, Climatic Change, 89, 179-193, 2007.

Menberg, K., Blum, P., Kurylyk, B. L., and Bayer, P.: Observed groundwater temperature response to recent climate change, Hydrol. Earth Syst. Sci., 18, 4453-4466, doi:10.5194/hess-18-44532014, 2014.

Miyakoshi, A., Uchida, Y., Sakura, Y., and Hayashi, T.: Distribution of subsurface temperature in the Kanto Plain, Japan; estimation of regional groundwater flow system and surface warming, Phys. 
Chem. Earth, 28, 467-475, doi:10.1016/S1474-7065(03)000664, 2003.

Mohseni, O. and Stefan, H. G.: Stream temperature air temperature relationship: a physical interpretation, J. Hydrol., 218, 128-141, doi:10.1016/S0022-1694(99)00034-7, 1999.

Monteith, J. and Unsworth, M.: Principles of environmental physics, Elsevier Science, Burlington, 2007.

Moore, R. D., Sutherland, P., Gomi, T., and Dhakal, A.: Thermal regime of a headwater stream within a clear-cut, coastal British Columbia, Canada, Hydrol. Process., 19, 2591-2608, doi:10.1002/hyp.5733, 2005.

O'Driscoll, M. A. and DeWalle, D. R.: Stream-air temperature relations to classify stream-ground water interactions, J. Hydrol., 329, 140-153, doi:10.1016/j.jhydrol.2006.02.010, 2006.

Ogata, A. and Banks, R. B.: A solution of the differential equation of longitudinal dispersion in porous media, US Geological Survey Professional Paper 411-A, US Geological Survey, Washington, D.C., 1961.

Oke, T. R.: Boundary layer climates, Methuen and Co., London, 1978.

Poole, G. C. and Berman, C. H.: An ecological perspective on instream temperature: natural heat dynamics and mechanisms of human-caused thermal degradation, Environ. Manage., 27, 787802, doi:10.1007/s002670010188, 2001.

Rau, G. C., Andersen, M. S., McCallum, A. M., Roshan, H., and Acworth, I.: Heat as a tracer to quantify water flow in near-surface sediments, Earth-Sci. Rev., 129, 40-58, doi:10.1016/j.earscirev.2013.10.015, 2014.

Reiter, M.: Using precision temperature logs to estimate horizontal and vertical groundwater flow components, Water Resour. Res., 37, 663-674, doi:10.1029/2000WR900302, 2001.

Reiter, M.: Possible ambiguities in subsurface temperature logs: Consideration of ground-water flow and ground surface temperature change, Pure Appl. Geophys., 162, 343-355, doi:10.1007/s00024-004-2604-4, 2005.

Rouse, W.: Microclimatic changes accompanying burning in subarctic lichen woodland, Arct. Alp. Res., 8, 357-376, doi:10.2307/1550439, 1976.

Scanlon, B. R., Healy, R. W., and Cook, P. G.: Choosing appropriate techniques for quantifying groundwater recharge, Hydrogeol. J., 10, 18-39, doi:10.1007/s10040-001-0176-2, 2002.

Snyder, C. D., Hitt, N. P., and Young, J. A.: Accounting for groundwater in stream fish thermal habitat responses to climate change, Ecol. Appl., doi:10.1890/14-1354.1, in press, 2015.

Snyder, D. T.: Estimated depth to ground water and configuration of the water table in the Portland, Oregon area, US Geological Survey Scientific Investigations Report 2008-5059, USGS, Reston, Virginia, 2008.

Stallman, R. W.: Computation of ground-water velocity from temperature data, in: Methods of Collecting and Interpreting Ground-Water Data: Water Supply Paper 1544-H, edited by: Bentall, R., USGS, Reston, Virginia, 35-46, 1963.

Stallman, R. W.: Steady one-dimensional fluid flow in a semiinfinite porous medium with sinusoidal surface temperature, J. Geophys. Res., 70, 2821-2827, doi:10.1029/JZ070i012p02821, 1965.

Steeves, M. D.: Pre- and post-harvest groundwater temperatures, and levels, in upland forest catchments in northern New
Brunswick, MSc Thesis, University of New Brunswick, Fredericton, NB, Canada, 222 pp., 2004.

St-Hilaire, A., Morin, G., El-Jabi, N., and Caissie, D.: Water temperature modelling in a small forested stream: implications of forest canopy and soil temperature, Can. J. Civil. Eng., 27, 10951108, doi:10.1139/100-021, 2000.

Story, A., Moore, R. D., and Macdonald, J. S.: Stream temperatures in two shaded reaches below cutblocks and logging roads: downstream cooling linked to subsurface hydrology, Can. J. Forest. Res., 33, 1383-1396, doi:10.1139/x03-087, 2003.

Studinski, J., Hartman, K., Niles, J., and Keyser, P.: The effects of riparian forest disturbance on stream temperature, sedimentation, and morphology, Hydrobiologia, 686, 107-117, doi:10.1007/s10750-012-1002-7, 2012.

Sutton, R. J., Deas, M. L., Tanaka, S. K., Soto, T., and Corum, R. A. Salmonid observations at a Klamath River thermal refuge under various hydrological and meteorological conditions, River Res. Appl., 23, 775-785, doi:10.1002/rra.1026, 2007.

Suzuki, S.: Percolation measurements based on heat flow through soil with special reference to paddy fields, J. Geophys. Res., 65, 2883-2885, doi:10.1029/JZ065i009p02883, 1960.

Tague, C., Farrell, M., Grant, G., Lewis, S., and Rey, S.: Hydrogeologic controls on summer stream temperatures in the McKenzie River basin, Oregon, Hydrol. Process., 21, 32883300, doi:10.1002/hyp.6538, 2007.

Taniguchi, M.: Evaluation of vertical groundwater fluxes and thermal properties of aquifers based on transient temperature-depth profiles, Water Resour. Res., 29, 20212026, doi:10.1029/93WR00541, 1993.

Taniguchi, M., Williamson, D. R., and Peck, A. J.: Estimations of surface temperature and subsurface heat flux following forest removal in the south-west of Western Australia, Hydrol. Process., 12, 2205-2216, doi:10.1002/(SICI)10991085(19981030)12:13/14<2205::AID-HYP730>3.0.CO;2-E, 1998.

Taniguchi, M., Williamson, D. R., and Peck, A. J.: Disturbances of temperature-depth profiles due to surface climate change and subsurface water flow: 2 . An effect of step increase in surface temperature caused by forest clearing in southwest western Australia, Water Resour. Res., 35, 1519-1529, doi:10.1029/1998WR900010, 1999a.

Taniguchi, M., Shimada, J., Tanaka, T., Kayane, I., Sakura, Y., Shimano, Y., Dapaah-Siakwan, S., and Kawashima, S.: Disturbances of temperature-depth profiles due to surface climate change and subsurface water flow: 1 . An effect of linear increase in surface temperature caused by global warming and urbanization in the Tokyo Metropolitan Area, Japan, Water Resour. Res., 35, 1507 1517, doi:10.1029/1999WR900009, 1999b.

Taylor, C. A. and Stefan, H. G.: Shallow groundwater temperature response to climate change and urbanization, J. Hydrol., 375, 601-612, doi:10.1016/j.jhydrol.2009.07.009, 2009.

Trumbo, B. A., Nislow, K. H., Stallings, J., Hudy, M., Smith, E. P., Kim, D., Wiggins, B., and Dolloff, C. A.: Ranking site vulnerability to increasing temperatures in southern Appalachian brook trout streams in Virginia: An exposuresensitivity approach, Trans. Am. Fish. Soc., 143, 173-187, doi:10.1080/00028487.2013.835282, 2014.

Uchida, Y. and Hayashi, T.: Effects of hydrogeological and climate change on the subsurface thermal regime in the 
Sendai Plain, Phys. Earth Planet. Int., 152, 292-304, doi:10.1016/j.pepi.2005.04.008, 2005.

USEPA - United States Environmental Protection Agency: Average temperature of shallow ground water map, available at: http://www.epa.gov/athens/learn2model/part-two/onsite/ ex/jne_henrysmap.html (last access: 2 February 2015), 2013.

van Vliet, M. T. H., Ludwig, F., Zwolsman, J. J. G., Weedon, G. P., and Kabat, P.: Global river temperatures and sensitivity to atmospheric warming and changes in river flow, Water Resour. Res., 47, W02544, doi:10.1029/2010WR009198, 2011.

Wagner, M. J., Bladon, K. D., Silins, U., Williams, C. H. S., Martens, A. M., Boon, S., MacDonald, R. J., Stone, M., Emelko, M. B., and Anderson, A.: Catchment-scale stream temperature response to land disturbance by wildfire governed by surfacesubsurface energy exchange and atmospheric controls, J. Hydrol., 517, 328-338, doi:10.1016/j.jhydrol.2014.05.006, 2014.
Webb, B. W., Hannah, D. M., Moore, R. D., Brown, L. E., and Nobilis, F.: Recent advances in stream and river temperature research, Hydrol. Process., 22, 902-918, doi:10.1002/hyp.6994, 2008.

Yoshikawa, K., Bolton, W. R., Romanovsky, V. E., Fukuda, M., and Hinzman, L. D.: Impacts of wildfire on the permafrost in the boreal forests of Interior Alaska, J. Geophys. Res., 107, 8148, doi:10.1029/2001JD000438, 2003.

Zhang, T. J.: Influence of the seasonal snow cover on the ground thermal regime: An overview, Rev. Geophys., 43, RG4002, doi:10.1029/2004RG000157, 2005. 